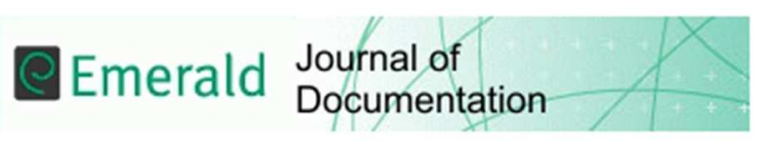

\title{
Evaluating patterns of national and international collaboration in Cuban Science using bibliometric tools
}

\begin{tabular}{|r|l|}
\hline Journal: & Journal of Documentation \\
\hline Manuscript ID & JD-11-2014-0164.R1 \\
\hline Manuscript Type: & Article \\
\hline Keywords: & $\begin{array}{l}\text { Building scientific capacity, Cuba, Scientific collaboration, Author Affiliation, } \\
\text { Science policy, Bibliometric }\end{array}$ \\
\hline \multicolumn{2}{|l}{} \\
\hline
\end{tabular}

SCHOLARONE

Manuscripts 


\begin{abstract}
Purpose - The study was designed to explore the hypothesis that collaboration was a key characteristic of Cuban science to maintain their scientific capacity during a period of economic restrictions and an important feature of Cuban science policy and practice for the benefit of society.

Design/methodology/approach - Collaboration was studied through Cuban scientific publications listed in PubMed for the period 1990 to 2010. The search was carried out using the advanced search engine of PubMed indicating $<\mathrm{Cuba}>$ in the affiliation field. To identify participating institutions a second search was performed to find the affiliations of all authors per article through the link to the electronic journal. A dataset was created to identify institutional publication patterns for the surveyed period. Institutions were classified in three categories according to their scientific production as Central, Middle or Distal: the pattern of collaboration between these categories was analyzed.

Findings - Results indicate that collaboration between scientifically advanced institutions (Central) and a wide range of national institutions is a consequence of the social character of science in Cuba in which cooperation prevails. Although this finding comes from a limited field of biomedical science it is likely to reflect Cuban science policy in general.

Originality/value - Using bibliometric tools the study suggests that Cuban science policy and practice ensure the application of science for social needs by harnessing human resources through national and international collaboration, building in this way stronger scientific capacity.

Keywords Author Affiliation, Bibliometric, Building scientific capacity, Cuba, Scientific collaboration, Science policy

Paper type Research paper
\end{abstract}




\section{Introduction}

International organizations and scholars have recognized Cuban scientific achievements even in those days when the country faced economic difficulties (Daar et al., 2002; López-Mola et al., 2006; De Vos et al, 2006), by pointing out strengths in the Cuban science and technology system. This article explores the patterns of Cuban scientific collaboration, whether or not it is an indication of the scientific capacity of the country supporting those achievements related to the health of the Cuban population.

Assessing scientific performance of a particular country implies the measurement of their scientific output, mainly through standard indicators used internationally to evaluate comparatively the science and technology performance of countries, nations or regions. However, the interest is to investigate if there is any distinctive patterns in Cuban scientific collaboration emerging from two characteristics that have been attributed to the culture and ethos of the Cuban scientific community when pursuing their aims: first, conducting their research through cooperation among institutions with different resources and expertise and second concentrating their effort on those topics affecting the Cuban population. Clark Arxer referred to these two features of the Cuban scientific community in the chapter about science in Cuba published in the UNESCO Science Report 2010: The current status of Science around the World (Clark-Arxer, 2011, 127) when explaining the case of Cuban biotechnology as the typical approach of the country's effort in research and development. Moreover, Clark-Arxer explained "national collaboration replaces competition amomg individuals as a driven force of Cuban biotechnology". This statement is explored through the study of the patterns of collaboration in Cuban scientific publications. Other features mentioned in this report included: the government as a source of investment, the implementation of a close linkage between research and commercialization, the generation of spin off state enterprises coming from scientific institutions and the harnessing of scientific effort for products that can reach foreign markets especially in the developed world (López-Mola et al., 2006).

Perhaps one of the first theories of scientific collaboration was developed by Donald Beaver and Richard Rosen in 1978 (Beaver and Rosen, 1978). Defining scientific collaboration as the collaborative scientific research acknowledged by co-authorships, Beaver and Rosen concluded that collaboration emerged as a result of the professionalism of science, first observed in France in the middle of the eighteenth century, and also found in other countries as the result of financial support for scientific activities (Beaver and Rosen, 1979). In this study, the author's 
affiliation was not considered when analysing collaborative scientific articles; the focus remained in demonstrating the origin of collaboration and the increasing number of co-authors, and the appearance of teamwork as a mode, later associated to the beginning of the "Big Science" (Price 1963, 90).

Some factors influencing this growth of scientific collaboration have been attributed to the interdisciplinary nature of breakthroughs in science and the increase in the connectivity between scientists all over the world by the revolution in digital communication and the access to the Internet (Stephan, 2012, 75), as well as the need of teamwork to overcome the degree of specialisation driven by the growth of knowledge (Price, 1963, 83). In a study examining trends in collaboration between 662 major U.S. universities Benjamin Jones and collaborators (2008) found that collaboration measured as co-authorship between universities was steadily increasing from the practically non-existent in 1975 to more than $30 \%$ of the publications in science, engineering and social sciences in 2005. The authors also found that collaboration between universities has a citation-impact advantage over collaboration within universities. Earlier in 1990, Narin and Whitlow found higher rates of citation of internationally collaborative papers compared to the rest of publications in a study of European scientific publications (Narin and Whitlow, 1990)

Evidence of how international collaboration in science emerged and developed came from studies analysing scientific publications dominated by advanced nations or those economies in transition with significant production of scientific articles (Luukkonen et al, 1992; Glänzel 2001). However, those studies have been relevant in establishing methodologically the way to evaluate this trend of increasing collaboration between nations.

An insightful approach linking international collaboration with the process of building scientific capacity in less developed nations was carried out by the team led by Caroline Wagner at RAND (2001). In this comprehensive report, which includes a study of 150 countries, the authors created an index of science and technology (S\&T) capacity for classifying those countries according to their development in S\&T. They also looked at whether collaboration between researchers from developed and developing countries might contribute to the process of building scientific capacity in those nations less developed.

It is therefore worthwhile exploring if any particular characteristic of the national and international collaboration of Cuban institutions might play a distinctive role in national 
development. To study the national and international collaboration of Cuban institutions we are selected the field of biomedical sciences because improving the health of the population has been a priority of the Cuban government since 1959 (Marimón-Torres and Martínez-Cruz 2010). This might explain why Cuba has health indicators typical of developed countries (Keck and Reed, 2012). Perhaps one of the most successful examples of developing science to support a high standard of public health is the case of immunology (Lage, 2012). Additionally biotechnology in Cuba followed a particular path for development, which embodied the social character of Cuban science (Reid-Simon, 2010, 168; Feinsilver, 1993, 122), delivering successful results to contribute to the country's economy (Pérez-Ones and Nuñez-Jover, 2009; Lage-Dávila, 2013, $145)$.

Cuban scientific output and collaboration have been systematically studied by bibliometrists (Araujo-Ruiz et al, 2005; Vega-Almeida et al 2007; Arencibia-Jorge and Moya-Anegón, 2010; Arencibia-Jorge et al, 2013 and Zacca-González et al, 2015) and their work has contributed to identify achievements and problems in the process of improving the scientific communication in the national system of scientific and technological innovation. Building on their contributions, the present work intends to address the leading role of more advanced institutions in a process of extending the scientific capacity of the country in a period of economic restrictions.

Although the number of scientific articles is a strong indicator measuring the effort of any particular country in the race to develop their capacities, there are other factors deciding the effectiveness of the inputs in developing S\&T, among them, the technological infrastructure and the adequate or optimal institutional coordination and cooperation (for more information about constructing an index for measuring scientific capacity see Wagner $(2008,121)$.

This exploratory study will look at evidence coming from Cuban scientific publications using bibliometric tools. Accepting the limitations this study might have, it should support further research into the role of scientific collaboration in Cuba and how it might be enabling the scientific capacity of the country for development.

\section{Design/methodology/approach}

There are advantages and disadvantages in choosing the appropriate database to access the information on scientific publications. PubMed as a free online database allowed us to carry out this exploratory study focussing on medicine and biomedical research. PubMed [1] was launched 
on the Internet by the National Library of Medicine in the United States in 1997. It currently comprises more than 24 million documents from more than 5,600 source journals in biomedical literature from MEDLINE and life sciences journals. It was one of the databases used to study the national health research priorities of Latin America and the Caribbean in addition to LILACS (Reveiz et al., 2013) suggesting its validity to study publications in health research in the region. One limitation of PubMed compared to Web of Knowledge (WoK) or Scopus is that this database did not show until 2014 all authors' affiliations, but only the address of the institution signing off the scientific paper. However, this feature can work to our advantage because the set of publications retrieved under author affiliation $<\mathrm{Cuba}>$ will be those publications in which Cuban institutions play a leading role. On the other hand, PubMed links to the electronic publications of peer reviewed journals allowed us to find and complete all author affiliations. We also considered the possibility of using the Cuban database called CubaCiencias held by the Scientific and Technological Information of the Republic of Cuba, but this database seems to require a better standardization in the field of author's affiliation, which is an essential part of our study (Araujo Ruiz et al, 2005). Another Cuban bibliographic database is Biblioteca Virtual en Salud (BVS) from the National Centre of Information in Medical Sciences (Infomed) including sources of information from Cumed, Ibecs, LILACS, MEDLINE, PubMed and Recu. However at the time we conducted this investigation, the search engine of BVS from Infomed did not include author affiliations in the available fields, not even in the advanced search, neither from Virtual Health Library (VHL), Bireme, Office of Pan-American Health Organization. Therefore PubMed is the most convenient database source for the purpose of this study at this stage. It may not give the best representative outputs to study the model of Cuban scientific collaboration, but will allow us to process enough information to have the preliminary view examining the role of Cuban scientific collaboration in the process of building national capacity, as well as identifying pitfalls for further studies. The implication of studying this selected sample means that the pattern of collaboration (or absence of it) has been decided by Cuban researchers/institutions, as well as the topics of the research involved.

\section{Search strategy and normalization process}

PubMed provides an Advanced Search for specific fields and we chose Affiliation with the word $<$ Cuba $>$, limiting the field of Publication dates to the years $<1990>,<1995>,<2000>,<2005\rangle$ and $<2010>$. Each set of Cuban documents per year was downloaded in an ad hoc dataset called SciPubCuba. PubMed also provides the direct link to the original document in the cases of 
electronic journals and therefore through that link a second search was carried out to obtain the affiliations of all authors. Some references were linked to the Latin American repository library online (Scientific electronic library online, ScieLO, Brazil) from which all authors' affiliations were also taken using ScieLO access to original document. This second search provided additional information, specifically institution names, to complete the field of all author affiliation in our SciPubCuba dataset. The percentages per year of documents in PubMed linked to the electronic journal (eJ-PubM) were: 1990 (2.3\%); 1995 (5.4\%); 2000 (62.3\%); 2005 (79.3\%) and $2010(80.4 \%)$.

Institution names were disambiguated from alternative English translations of the same name helped by author knowledge of those places in question and by searching in the Internet about their location and function. In some cases, electronic e-mails to the corresponding author were sent to confirm the name and location of the affiliations. Disambiguation of different names or acronyms in Spanish was also performed as well as a manual inspection to eliminate false documents.

The normalization of the qualitative evaluation of the content of the Cuban scientific production was carried out by individual and manual inspection of the content of the publication (only eJPubM) classifying them by disciplines and type of health subjects.

Disciplines and health subjects were classified by integrating the content of title of the publication, departments involved in the affiliation and the journal title. For instance: in the article "Clonal distribution of disease-associated and healthy carrier isolates of Neisseria meningitidis between 1983 and 2005 in Cuba" the discipline was classified as "MOLECULAR BIOLOGY" according to the main department involved: "Department of Molecular Biology, Division of Biotechnology, Finlay Institute". For the health subjects we classified this publication as "CERTAIN INFECTIOUS and PARASITIC DISEASES (I)" according to the content of the title and the scientific journal in which it was published: "Journal of Clinical Microbiology". Health subjects were classified according to the International Classification of Diseases (IDC$10^{\text {th }}, \mathrm{WHO}, 2015$ ) and related health problems, which is commonly used to provide uniform views of the health situation of countries and populations. Some disciplines and health subjects were grouped because they often are closely related (shown in figures 7 and 8). When more distant disciplines and health subjects were parts of the research published, they were considered MULTIDISCIPLINARY. Articles in applied research addressing explicitly a disease were 
counted for the mentioned health problem even if the contribution came from institutions of nonmedical research or services.

The retrieval of scientific articles from PubMed was concluded in December 2013. Due to the small PubMed coverage of electronic journals for 1990 and 1995, those years were excluded in this study.

\section{Datasets SciPubCuba and CubanInstitutions}

SciPubCuba was our reference dataset in which each document corresponding to a scientific article received an identification reference number (IRN) for each studied year. The PubMed reference number was also kept as a second alternative identification. CubanInstitutions was our working dataset created in Excel with the names of Cuban institutions as their names were appearing in the search. A record of Cuban institutions and their IRN per publication per year was created to count and classify their articles according to the nature of their collaboration.

SciPubCuba outputs are net publications ascribed to only one institution with a unique IRN and PubMed number. Thus, total net publications (TNP) was the aggregate number of publications for the years 2000, 2005 and 2010 and it was obtained from this reference dataset, therefore

$\mathrm{TNP}=\Sigma(\operatorname{IRN} i)_{2000}+\sum\left(\mathrm{IRN}_{j}\right)_{2005}+\sum(\mathrm{IRN} k)_{2010}$

In this case $i, j$ and $k$ are unique articles in 2000, 2005 and 2010 respectively.

CubanInstitutions was our working dataset created with the list of Cuban institutions (column) and their articles (IRNs per row) per year (sheets). Articles per institution were then classified in four types: only one institution $(\mathrm{N})$, more that one national institution $(\mathrm{NN})$, only one national institution with one or more international collaboration (NI) and more than one national institution with one or more international collaboration (NNI).

Institutional publications (IP) accounted for all articles in which the institution participated regardless of the position of the author affiliation and is obtained by counting their IRNs (integer counting) per institution and year. The total institutional publications (TIP) were obtained by adding the IPs of all institutions in aggregate for the years 2000, 2005 and 2010. Therefore, 
$\mathrm{TIP}=\sum(\mathrm{IP} i)_{2000}+\sum(\mathrm{IP} j)_{2005}+\sum(\mathrm{IP} k)_{2010}$

In this case $i, j$ and $k=$ institutional publications in 2000, 2005 and 2010 respectively

A diagram of the experimental design used in this study is shown if figure 1.

Defining institutions according to their publication outputs and functions

For the purpose of this study, which focused on biomedical science, publications of the Cuban institutions were classified according to the number of their IPs in the aggregated years regardless of the status or tiers of the institution in the National Science and Technology System. The top 20 more productive institutions were called Central group; those institutions with less than 5 institutional publications were called Distal group including 156 out of 201 Cuban institutions; and those in between these two groups including 25 institutions were called Middle group. Although it is an arbitrary division, it allows us to create a setting in which more active researchers working in top institutions (Central) publish with transient collaborators in geographically dispersed institutions (Distal), typical behaviour in scientific communication first described in the study of the Information Exchange Group 1 (IEG 1) on Oxidative Phosphorylation and Electron Transport Chain (Price and Beaver, 1966). Other scatter or skew distributions have been described for journals, known as Bradford's Law, or for author productivity known as Lokta's Law (Sen, 2010). However we are not aiming to prove if Cuban scientific publications in biomedical sciences follow or not any particular distribution. We are interested to study the relationship between contributing institutions with different resources and expertise through their national and international collaboration and how it might strengthen Cuban national scientific capacity.

The institutions were also classified according to their principal role such as higher education, research and development, services and production, etc. In the majority of cases the name of the institution indicates their function as universities (and polytechnics) and were considered higher education (HE) and Science \& Technology (S\&T). In the case of medicine, Cuba has national institutes of different specialties such as Institute of Cardiology and Cardiovascular Surgery (in Spanish as ICCC), classified as research institutes-Hospitals; other research institutions (R\&D) in the Ministry of Health were not hospitals such as Centre for Research and Development of Medicaments (in Spanish as CIDEM); Teaching hospitals (TH) were separated from general hospitals $(\mathrm{GH})$ and specialized hospitals $(\mathrm{SH})$ such as maternity hospitals, which are mainly 
service (S). Other national, provincial or municipal institutions were also classified as centres aiming to improve the public health such as the National Centre for Quality Control of Medicaments (CECMED), or Provincial Centre of Hygiene and Epidemiology of Santiago de Cuba, or Municipal Unit for Surveillance and Control against Vectors in Cumanayagua, Cienfuegos. Although classification of all institutions might look too specific, we decided to keep details showing the geographic distribution of them especially in the Distal group.

Once the three groups of institutions were established the nature of national and international collaboration between Central institutions with the other two groups was explored through graphic representation of the multivariate data available in Excel. Data was prepared in two spreadsheets of collaborative IPs per institution of the Central group for the analysis of the national and international collaboration. For both sets of data IPs showing collaboration within Central and with Middle and Distal were counted and each institution received equal recognition regardless of the position of the author affiliation, but counted only once in the case of more than one author per institution.

Other sources used supporting the analysis of scientific outputs in the context of Latin American and the Caribbean were: Science Citation Index (SCI), Thomson and Reuters and SCImago journals and country rank (SJ\&CR), powered by Scopus database, Elsevier as well as Science and Engineering indicators (NSF 2000 and 2014) from National Science Foundation, United States of America. Additionally we used the World Bank data for normalizing the number of publications per inhabitants of the countries of interest available at The World Bank website [3].

\section{Results}

\section{Cuban scientific outputs retrieved from PubMed}

Scientific output of Cuban institutions measured by the number of publications retrieved from the PubMed database using advanced search is shown in Table 1. The number of total net publications (TNP) in aggregate for the year 2000, 2005 and 2010 was 861 from which 646 were further completed in the field of all authors affiliation using the electronic Journals linked to PubMed (eJ-PubM), representing $75 \%$ of the all articles in the aggregated years. Cuban collaborative articles represented $60.2 \%$ of those articles that were further completed with all author affiliations.

Pattern of collaboration measured through Cuban institutional publications 
All Cuban institutions shown in the author affiliations of the eJ-PubM sample were listed with their publications classified as $\mathrm{N}$ (only one Cuban institution) and NN (more than one Cuban institution), NI (one Cuban institution and one or more international institutions) and NNI (more than one Cuban institution and one or more international institutions) for the years 2000, 2005 and 2010 .

The total aggregate number of institutional publications (TIP) was used to classify the groups in Central, Middle and Distal as described under methods. Table 2 shows the distribution of Cuban institutions according to their output in scientific publications and their main function. Institutions in the Central group represented $10 \%$ and Middle and Distal groups $12.4 \%$ and $77.6 \%$ of all institutions respectively. Among the two hundred and one institutions listed 23.5\% belong to Higher Education, 25.5\% are institutions of Research and Development, 15.5\% are Research and Services/Production and 35.5\% are institutions either supporting the National Health System or dedicated to production or services. All institutions in both Central and Middle groups are all involved in research while in the Distal group it is only $54 \%$.

[Appendices 1 (Central group), 2 (Middle group) and 3 (Distal group): Cuban institutions (201) listed from the author affiliations found in the articles of electronic journals linked to the publication records in PubMed.]

The total net scientific papers (TNP) in aggregate for the three years were 646 articles from eJPubM. However, when counting them as institutional publications the total number of scientific papers reached 980 articles (TIP) indicating the degree of participation of more than one institution per scientific article.

Collaborative papers including national and international institutions represented $60 \%$ of the 646 net publications (Table 3). The Central group as expected (Price and Beaver, 1966) representing $10 \%$ of all institutions generated 497 articles accounting for $76.9 \%$ of the total net publications while the Distal group of 156 institutions contributed with $10.4 \%$ to the net publications. The proportion of collaborative articles including the participation of national and international institutions were 58.8\%, 69.5\% and 59.7\% for Central (C), Middle (M) and Distal (D) groups respectively related to total net publications (TNP) per group (sub-TNP). However, the collaborative net publications are concentrated in the Core group and represents $45.2 \%$ (292 articles out of 646), while $\mathrm{M}$ and $\mathrm{D}$ only contribute with $8.8 \%$ (57 out of 646 ) and $6.2 \%$ (40 out of 646). Obviously these values do not fairly represent the real contribution of institutions in $\mathrm{M}$ and $\mathrm{D}$ groups to the collaborative scientific output of Cuban institutions since as net publications, 
articles are attributed only to the first author affiliation.

Institutional publications (IP) allow analysis of the pattern of collaboration and the relationship among national institutions in which all participating institutions were accounted for their contributions to the article regardless of the position of the institution in the list of contributing authors. Collaborative articles both involving national or international co-authorships and counted by IPs represented 74\% of 980 IPs. Articles with more than one Cuban institution (NNs) either national or international represented $75 \%$ of collaborative papers (only NI excluded from collaborative papers) indicating the strong relationship among Cuban institutions (Table 3), with the Central group leading the cooperation (38.9\%), followed by the Distal group with $22.3 \%$.

\section{National Collaboration}

The Central group provides the focus for the analysis of the pattern of collaboration through the relationship of their collaborative papers with the institutions within the Central (C) group and with the Middle (M) and Distal (D) groups using IPs as a source of data. In general there is a linear relationship ( $\mathrm{y}=2.2 \mathrm{x}$ and $\left.\mathrm{R}^{2}=0.899\right)$ between the amount of collaborative papers within the $\mathrm{C}$ group (NN-C) and the total number of national collaborative papers (Figure 2A), accounting for $50 \%$ of national collaboration. The top five institutions by the volume of their publications contribute more to the collaboration within the Central group, as they are part of the Scientific Park in West Havana. Those institutions with a higher volume of publications (larger diameter of the circles) are the Institute of Tropical Medicine Pedro Kourí (IPK) with 141 papers, the Centre of Genetic Engineering and Biotechnology (CIGB) with 130, University of Havana (UH) with 104, National Centre of Scientific Research (CNIC) with 59, University of Villa Clara (UCLV) with 36 and the Centre of Molecular Immunology (CIM) with 34. The next institutions of the Central group which fit less to the linear relationship of NN versus NN-C are the National Institute of Neurology and Neurosurgery (INN), Hospital "Hermanos Amejeiras (HHA), Centre of Pharmaceutical Chemistry (CQF), Cuban Neuroscience Centre (CNC), National Institute of Oncology and Radiology (INOR), Higher Institute of Medical Sciences of Havana (ISCM-H) and Institute of Nephrology “Abelardo Buch" (IN-AB). The last sub-group of institutions in the Central group with the lowest contribution in terms of national collaborative papers are Central University of Las Villas (UCLV), International Centre for Neurological Restoration (CIREN), Finlay Institute (IF), University of Oriente (UO), Higher Institute of Technologies and Applied Sciences (InSTEC), Centre of Immunoassay (CIE), National Centre of Animal Health (CENSA) and University of Matanzas Camilo Cienfuegos (UM-CC). 
The collaboration of the institutions of the $\mathrm{C}$ group with the ones of the $\mathrm{M}$ and $\mathrm{D}$ groups did not follow a linear relationship (Figure 2B). The majority had stronger collaborations with institutions in the D group, as the relation M:D shows for IPK (1:3), HHA (1:2), UO (0:4), CQF (1:3), CENSA (0:3) and IN-AB (4:9). Leading the institutions with stronger collaborations with those of the M group are the CNIC (12:5) and ISCM-H (3:1). The rest of the institutions collaborated almost equally with institutions in $\mathrm{M}$ and $\mathrm{D}$ groups. Interestingly, the strong collaboration of CNIC with M group might indicate the role of this institution as incubator of spin-off institutions (either research or state enterprises) with a defined profile of applied science.

\section{International collaboration}

International collaboration of Cuban institutions has been increasing steadily since 2000 with European institutions sharing the highest presence in collaborative papers with Cuban institutions (Figure 3). Fourteen European countries have co-authored 249 articles with Cuban institutions when looking at the aggregate data of institutional publications; and in 2010 the European countries with more collaborative papers with Cuba were Spain (46; 36.2\%), Belgium $(17 ; 13.4 \%)$, Germany $(16 ; 12.6 \%)$ and United Kingdom $(14 ; 11 \%)$ out of 127 collaborative IP. Nine Latin America countries participated in collaborative papers in the period of study accounting for 100 IPs and in 2010 the Latin American countries with the highest share were Brazil (25; 39.7\%), Argentina (15; 23.8\%) and Mexico $(10 ; 15.9 \%)$ out of 63 collaborative IPs. Japan is the individual country with highest share per region with $44 \%$ of collaborative papers in 2010. For North America, in spite of being the region of highest output in science, the share of collaborative papers with Cuban institutions has been relatively lower with only 35 collaborative IPs; and in 2010 both Canada (6; 46\%) and United States (7; 54\%) were similarly represented for a total of 13 articles. In 2010 all regions except Africa were publishing in collaboration with Cuban institutions. International organizations such as WHO, UNESCO and PAHO have been represented through their experts co-authoring papers with Cuban institutions with 2 and 6 publications in 2000 and 2010 respectively. For the years included in this study, countries publishing with Cuban institutions were: Argentina, Brazil, Chile, Colombia, Mexico, Nicaragua, Paraguay, Peru, Puerto Rico, Canada, United States, Austria, Belgium, Finland, France, Germany, Italy, Portugal, Spain, Sweden, Switzerland, United Kingdom, Russia, Bangladesh, Cambodia, China, Iran, India, Japan, Korea, Malaya, Philippines, Singapore, Syria, Thailand, Vietnam, Uzbekistan, Australia and New Zealand. 
Collaborative papers with international institutions represented $41 \%$ of the total net publications (266 out of 646). When analysing the contribution of each group of institutions to the total IPs in terms of publications with at least one international institution (NI+NNI), all institutions in the $\mathrm{C}$ group co-authored 261 papers (69\%); 24 out of 25 institutions of the M group participated in 47 papers (12.4\%) and only 51 out of 155 institutions of the D group contributed participating in 70 papers $(18.5 \%)$ for a total of 378 IPs involving international collaboration (Table 3). For institutions in $\mathrm{M}$ and $\mathrm{D}$ groups national collaboration $(\mathrm{NN})$ is stronger (50\% and 53\% respectively) versus international (33\% and $34 \%$ respectively) in relation to their own institutional publications.

The contribution to the total international collaboration of individual institutions in the Central group publishing with one or more international institutions (NI) was $80.4 \%$ (for NI: 144 out of 179 IPs) and 58.8\% (for NNI: 117 out of 199 IPs) when other Cuban institutions were participating in the collaborative articles (see Table 3). The leading role of the Central group incorporating institutions in $\mathrm{M}$ and $\mathrm{D}$ groups is shown in Figure 4, with the Institute of Tropical Medicine Pedro Kourí (IPK) sharing almost 80\% with D institutions in those articles including another Cuban institution. Another eleven institutions of the Central group share a third or more of their international collaboration with institutions of the Distal group.

\section{Evolution and content of the Cuban scientific collaboration}

International collaboration between scientific institutions co-authoring articles in science and engineering ( $\mathrm{S} \& \mathrm{E})$ is another important feature strengthening the countries capabilities in scientific research and development. International co-authored articles in S\&E have increased by $133 \%$ from 90,867 articles in 1997 to 211,841 in 2012 and United States remains the strongest hub for scientific collaboration in the world stage (NSF 2000 and 2014).

After the collapse of Soviet Union and socialist countries of Eastern Europe at the beginning of 1990, Cuba evolved her pattern of international collaboration probably as a way to maintain the commitment for the development of science initiated since the early 1960s. Figure 5, generated from data of the National Science Foundation, Science and Engineering indicators (NSF 2000), shows how different is the pattern of Cuban international collaboration from other countries of the region. Latin American countries as shown in the figure 5, shared 32\%- 55\% of their internationally co-authored articles with the U.S. in the period before and after 1990, while Cuba showed a distinctive turn in the pattern in which the collaboration with Soviet Union was 
replaced by Spain. Diversification of the international collaboration was also characteristic of this period by producing collaborative articles with countries such as Canada, Belgium, Denmark, Japan and Austria, as well as increasing the share of scientific collaborative articles with others such as the United Kingdom, Switzerland and France (NSF 2000). Even with the United States, Cuba experienced an increase in scientific collaboration regardless of the geopolitical distance between both countries.

At the beginning of this century Cuban scientific output measured by the number of articles published in international journals has been shown to be not far from the mean of the Latin American and the Caribbean (LAC) scientific articles when normalized by population (ClarkArxer, 2010), being slightly higher in 2001 and lower in the following years up to 2007. In general, for some countries, the evaluation of scientific output changes depending on the sources used to obtain the science and technology indicators, as two different results might arise by counting scientific articles either from Science Citation Index (SCI), Thomson and Reuters or from SCImago journals and country rank (SJ\&CR), powered by Scopus database. Latin American countries are better represented in Scopus than in SCI (Science Citation Index) and Cuba ranks in fifth (NSF, Figure 6) or fourth (SJ\&CR, Figure 6) positions in the amount of scientific and engineering (S\&E) articles for the region accounted by S\&E articles per million of population. Using SJ\&CR [2] we found that more than a third of total publication in these top seven countries of the LAC correspond to international collaboration for the period 2000-2010 with Chile, the leading country in the table, having $52.5 \%$ of international collaboration, followed by Colombia (52.1\%), Cuba (44.9\%), Venezuela (43.5\%), Mexico (40.2\%), Argentina (40.5\%) and Brazil (27.8\%).

In our study limited to a cross section of aggregated publications for the years 2000, 2005 and 2010 in which all author affiliations were recorded, we found as expected, that the disciplines contributing more to overall publications were immunology and microbiology $(19.7 \%)$, the group of biochemistry- molecular biology - biotechnology $(18.6 \%)$, medicine $(15.6 \%)$ and the group of pharmacology- toxicology -pharmaceuticals $(15.2 \%)$; interestingly the group of chemical sciences (16.1\%) had strong representation, which denotes its role supporting biomedical research in structural and molecular biology (figure 7). This result is an expression of national policies to advance science to improve the health of the Cuban population and to stimulate innovation in areas that can reach foreign market such as biotechnology. Immunology and microbiology are essential disciplines in the diagnosis, cure and prevention of transmittable 
diseases, including the development of new vaccines. Immunology is also a key discipline in Cuban approach to develop technologies of immunotherapy in the treatment of cancer. The groups with less collaborative articles are immunology-microbiology and medicine with 46\% and $48 \%$ respectively compared to the total of $60 \%$. The case of immunology-microbiology seems to be a consequence of the high representation of articles related with infectious diseases in PubMed since Revista Cubana de Medicina Tropical is the only Cuban journal indexed in this database. Indirectly it might suggest that disciplines other that immunology and microbiology only have a selected representation in PubMed, in which collaborative articles are strong candidates to be accepted in foreign journals. In the case of medicine the observed low collaboration has been attributed to the degree of specialisation of the National Institutes of Health (Vega-Almeida, 2007) and publications by departments in hospitals concerning their own findings and report of cases. Low collaboration in the health sector has been also shown in other studies (Arencibia Jorge et al., 2013, Zacca González et al., 2015) and might be the reason why the output in the sector is less than the expected.

Not surprisingly, the classification of the articles by diseases and health disorders showed the same trend with more representation of scientific contribution in infectious diseases (46\%), cancer $(13 \%)$ and disorders of the nervous system (16\%) as shown in Figure 8. However, in general articles contributing explicitly to a particular disease or disorder account for 309 publications meaning that $62 \%$ of this output came from institutions that do not belong to the health sector, but their applied research addressed priorities of the national health system and consequently the proportion of scientific collaboration rose to $69 \%$.

The case of "dengue" an endemic tropical disease affecting the Cuban population illustrates the priority given by the government to support research for public good. Research in this topic attracts only by $0.1 \%$ of the total publications in Medline $(3,456$ out of $3,460,987)$. However because of the frequent outbreaks of this infectious disease, research in dengue has been a priority in the Cuba National Research Programme explaining why Cuba reaches the fourth in the ranking of national interest among 79 countries with $4.6 \%$ of its total publications in this field and sharing $1.94 \%$ of international publications in dengue for the $14^{\text {th }}$ ranking (values calculated on $20^{\text {th }}$ June 2014 from the available search engine in Medline/PubMed developed by Corlan, 2012). 
Biomedical and biosciences research are generally supported by multiple disciplinary teams and it is sometimes difficult to separate the boundaries between them, however in many cases, one discipline takes the centre of the contribution (Vega-Almeida, 2007).

\section{Discussion}

Developing countries have been in constant challenge adapting their resources to improve their capacities to compete on the world stage for the benefit of their societies. With the advent of the knowledge society, the economic growth and social welfare of a country will depend more on the degree of development of its science, technology and innovation system. Although harnessing science and technology resources in these countries depends on several factors, scientific collaboration, both national and international, surely will strengthen their national scientific capacities.

In this study of analysing national and international collaboration of Cuban institutions we explored how to evaluate two characteristics of Cuban science and the possible implications in passing on the benefit of scientific research to Cuban society, while improving the national scientific capacity. It seems that these two characteristics of conducting their research through cooperation among institutions with different resources and expertise and secondly concentrating their effort on those topics affecting the Cuban population helped not only to strengthen the collaboration among top Cuban institutions, but to take science to a broader set of institutions not necessary involved in S\&T. Nuñez-Jover and López-Cerezo, (2008) explained the makeup of Cuban scientists as it is described in the content of the Code on Professional Ethics of Cuban Scientists, "While scientists are required to seek the truth and carry out honest and disinterested work to contribute to the advance of science, the main contribution expected from this work is social welfare, to which individual and corporate interests must be subordinated" And it seems that this combination of ethics and political will was not only ideological, but practically the only way to survive isolation under circumstances of frequent epidemics suffered by the population in which what was called initially the "Biological Front" and later the "Scientific Pole", played a crucial role. Hostility against the will of the nation to defend the social system turned the inefficiency of the early years in which scientific results did not necessarily translate to innovation, into a network of institutions, strategies and policy aiming to maintain the health of the population and the creation of new sources of export, based on knowledge and innovation. 
The strategy of choosing PubMed in order to have those publications related to Biomedical and life sciences might also help to access the best Cuban scientific publications. Cuban institutions might selectively publish in international journals those articles strengthened by collaboration, both national and international. Although the evidence from previous years (1989 to 1994) indicated that Cuban scientists increased their publications in international journals by $211 \%$, while decreasing by $60 \%$ the amount of publications in Cuban journals due to a lack of resources in the Cuban publishing sector (Araujo et al., 2005).

We found that $30 \%$ of net publications involved more than one Cuban institution (data not shown), and is similar to that found for the multi-university collaboration among US schools in Science and Engineering (Jones et al., 2008) with 32.8\% in 2005, which might indicate that Cuban institutions follow the international trend rather than a particular pattern to overcome the economic restrictions during the period post 1990. In another study using co-authorship bibliometric analysis to evaluate collaboration in countries of Latin American and the Caribbean (period 1995-2002), the authors found that the overall collaborative publications represented $65 \%$ of the total (Sancho et al., 2006). Moreover, the authors found that national and international collaboration of the region represented $26.4 \%$ and $35.5 \%$ respectively, with a very limited regional collaboration (2.7\%) with the exception of Cuba with $26 \%$. In this study the authors used the SCI database and recognized that the representation of Latin American journals is still very low representing only $0.6 \%$ of the total. We also found that $40 \%$ of net publications of Cuban institutions were with international partners (data not shown) equally following the global trend (The Royal Society, 2011, p 4). As it was pointed out in this report, "scientists seek for excellence in their work by sharing tasks, costs and experience", and in the case of Cuba, under the circumstances of this period, it might also have a component of outsourcing to ensure access to otherwise limited materials and modern equipment. This also suggests that in addition to the government support for areas of applied research related to population needs, the Cuban researchers actively seek collaboration to advance science in subjects of local interest.

Galvez and collaborators (2000) found that paradoxically developed nations, which accrued more than $85 \%$ of world publications, are less inclined to collaborate internationally and at the same time had more transnational publications. International collaboration was $20 \%, 24 \%$, and $39 \%$ for North America, Asia and Western Europe respectively, while for Latin America and the Caribbean, Southern Africa, Northern Africa and Eastern Europe was 62\%, 59\%, 58\% and 52\% respectively. The reason, they argue, seems to be that developing nations were becoming more 
dependent on developed nations, not only economically, but also scientifically. At the same time nations with strong economies naturally tend to develop strong scientific communities (Galvez et al., 2000) among themselves. Although their results seems to support their views, this conclusion came from analysing a relatively short period between 1991 -1998, and using Science Citation Index, which did not evenly cover all regions. While the current study was carried out Zacca and colleagues (2014) showed that collaboration was a key factor behind the development of scientific activities in Latin America in this century. The areas covered in this article were public health and environmental and occupational health and the database used was SCImago Journal and Country Rank. Interestingly they found that Cuba, Colombia and Brazil had the greatest strengths measured by thematic specialization among the countries with most scientific output (Brazil, Mexico, Cuba, Colombia and Argentina).

An unexpected result was the lack of international collaborative articles with Africa as a region, especially when there is a long lasting policy of international cooperation between Cuba and more than 38 countries of the region (Marimón Torres and Martínez Cruz, 2010) in the area of public health. This finding might reflect the difficulties that still prevail in publishing scientific results in some areas of the health sector in which they concentrate more in delivering and reporting the service rather than publishing in scientific journals. This problem also affects the international visibility of Cuban science (Arencibia-Jorge and Moya-Anegón, 2010). It would be interesting to explore why this long-term cooperation with countries in Africa does not correspond to more international scientific publications.

We represented the pattern of Cuban collaboration through the institutional publications and not through the net publications to give equal representation to all participating national institutions. This approach revealed that the Central group is leading the cooperation with almost equal proportion of participation among the three groups. Seventy per cent of Central institutions have articles with institutions in the Distal group. The Institute of Tropical Medicine Pedro Kourí (IPK) showed the highest cooperation with the Distal group with a wider number of institutions often in the same article. Two other institutions by virtue of their policies showed strong collaboration within the Central group and the Distal group: these are University of Havana (UH) (Pérez Ones and Nuñez Jover, 2009) and Centre of Genetic Engineering and Biotechnology (CIGB)(López Mola et al., 2006). This interaction between the Central group and the rest of the institutions seemed to be different to the study of Jones and collaborators, in which they found that the multi-university collaboration is more stratified by in-group university 
ranking. However we should stress again the small size of our sample in contrast to 4.2 million articles analysed for a period of three decades (Jones et al., 2008). Our approach focused in the relationship between the most scientifically productive institutions with a wide range of institutions distributed along the country. By taking this approach we centred the attention in the role of leading scientific institutions sharing their resources and experience with less scientifically productive institutions but directly connected either to services or production. Another approach was used describing the production of knowledge and the role of collaboration between different sectors in Cuba by assessing the model of Triple-Helix (Arencibia-Jorge et al, 2013), which might fit better for more developed nations. Similarly, when combining bibliometric, socioeconomic and health indicators in the analysis of Latin American output in public health (Chinchilla Rodríguez et al, 2015), the authors could not find that the tangible achievement in health attained by Chile and Cuba were the result of their publishing pattern in the area of public health. Perhaps a combination of those methodologies will lead to better characterise the Cuban scientific performance and its social implications in the science, technology and innovation system of the country. It might be plausible in the future to focus on the rise and evolution of scientific parks and in the role played by older universities fostering scientific research in newly created universities and campuses. Scientific parks embody the essence of the Mode 2 of production of knowledge, described as socially distributed, application orientated, trans-disciplinary and subject to multiple accountability (Nowotny et al, 1996). In the case of Cuba there are other stakeholders within the public sector supporting the process of knowledge production and innovation, such as Youth Technology Brigade (BTJ), with more than 200,000 members and the National Association for Innovation and Rationalizations (ANIR) with 100,000 members (Nuñez Jover and López Cerezo, 2008).

The key decision for further studies would be choosing the source of information among all available databases representing Cuban output in science. Previous studies evaluating the total scientific production of Latin America and the Caribbean region (Miguel, 2011) found that in the case of Cuba, $48.6 \%$ of Cuban journals (151) listed in LATINDEX were covered by SciELO (70.5\%), RedALyC (37.3\%) and Scopus (41.2\%) as electronic databases with different platforms supporting the search and retrieval for bibliometric studies. Moreover, the study of Araujo Ruiz and collaborators (2005) showed that the Institute Scientific Information Databases (ISI-DBs) indexed only $20.7 \%$ of Cuban articles when compared to the local database CubaCiencias during the period between 1988 and 2003. In a macro level study of Cuban scientific output combining socioeconomic and bibliometric indicators, the authors concluded that Scopus was a better 
information source when it was compared to WoS (Arencibia-Jorge and Moya-Anegón, 2010). Obviously, studies addressing the visibility of Cuban science in which the databases provide the engine for analysing the citation of articles might still need to use those databases with less than $50 \%$ representation of Cuban outputs in science. However, when focussing on how Cuban scientific and engineering outputs have contributed to build the scientific capacity of the country and the implication of policies to bring scientific results to society, searching nationally generated databases and documents will provide more information.

\section{Conclusion and future directions}

In spite of the limitations mentioned above, our results indicate that collaboration between scientifically advanced institutions (Central) and a wide range of national institutions is a consequence of the social character of science in Cuba in which cooperation rather competition prevail (López-Mola et al., 2006). The conclusion comes from a search in the limited field of biomedical science but it might be representative of Cuban science. The Cuban government has supported areas of biomedical research not only to improve the health of the Cuban population but also to strategically create sources of income from high level biotechnology research as well as expanding its capacity to effectively co-operate with developing countries and emerging economies (Sáenz et al., 2010, Keck and Reed, 2012). However, given the economic restrictions of the period of study it seems that the nature of this collaboration was a decisive component for success. Probably extending the search to other fields such as social sciences will allow the study of more features of Cuban collaboration as it could be foreseen from the model of Yaguajay (Lage-Dávila, 2004).

Further studies will also explore the nature of collaboration between Cuban scientists working in the country and those abroad using Scopus as a database. One of the advantages of Scopus is the scientist identification number, which allows the following of the movement of the researcher through different institutions and countries during their working life (Plume, 2012). Migration of highly skilled citizens towards developed countries has been increasing in the last decades (Docquier and Rapoport, 2012) and developing countries are looking for policies to harness the potential lost through the brain drain (Le Bail and Shen, 2008). Indeed, contributions from the outcome of transnational knowledge through diaspora networks have been documented (Guchteneire et al., 2006, Mahroum et al, 2006) 
Human capital is the vital asset of Cuban science: highly skilled and trained to perform not always under optimal conditions, they embodied creativity, resilience and perseverance, all essential in a scientist (Stone, 2015). However human capital is mobile and can reach resources anywhere any time; and by the same token a risk of migration might be a threat to the effort of building scientific capacity.

The creativity in overcoming difficult times seems to be part of the idiosyncrasy of Cuban socialism and there are many instances in which cooperation works as leverage to create knowledge and innovation (Núñez Jover, 2010, 135; Lage Dávila, 2013, 145 ).

Endnotes:

[1] Information updated on $24^{\text {th }}$ September 2014 at http://www.ncbi.nlm.nih.gov/pubmed and http://www.nlm.nih.gov/pubs/factsheets/pubmed.html

[2] SJ\&CR: SCImago Journal and Country Rank, powered by Scopus. Information accessed on $17^{\text {th }}$ September 2014. http://www.scimagojr.com/countrysearch.php?country=EC

[3] The World Bank. Information accessed on $17^{\text {th }}$ September 2014. http://data.worldbank.org/indicator/SP.POP.TOTL 


\section{References}

Araujo Ruiz, J.A., Van Hooydonk,G., Torricella-Morales, R.G. and Arencibia, R. (2005), "Cuban scientific articles in ISI Citation Indexes and CubaCiencias databases (1988-2003)", Scientometrics, Vol. 65, No. 2, pp. 161-171.

Arencibia-Jorge, R. and Moya-Anegón, F. (2010), "Challenges in the study of Cuban scientific output". Scientometrics, Vol. 83, No. 3, pp. 723-737.

Arencibia-Jorge, R., Vega -Almeida, C.R., Araujo-Ruiz, J.A.,Corera Alvarez, C.E. and MoyaAnegón, F. (2012), "Milestones of the Cuban Science in the XXI century, a review of the most cited papers in Scopus, 2001 -2005" ACIMED, Vol. 23, No.1, pp. 45-58.

Arencibia-Jorge, R., Corera-Alvarez, C.E., Chinchilla-Rodriguez, Z. and Moya-Anegon, F.. (2013), "Intersectoral relationships, scientific output and national policies for research development: a case study on Cuba 2003-2007". Revista Cubana de Información en Ciencias de la Salud, Vol. 24, No. 3, pp. 243-254.

Beaver, D. dB. and Rosen, R. (1978), "Studies in scientific collaboration: PART I. The professional origins of co-authorship". Scientometrics, Vol. 1, No. 1, pp. 63-84.

Beaver, D. dB. and Rosen, R. (1979), "Studies in scientific collaboration: PART IIII Professionalization and the natural history of modern scientific co-authorship". Scientometrics, Vol.1, No.3, pp 231-245.

Chinchilla-Rodríguez, Z., Zacca-González, G., Vega-Quesada, B. and Moya-Anegón, F., (2005), "Latin American scientific output in Public Health combined analysis using bibliometric, socieconomic and health indicators", Scientometrics, Vol. 102, pp. 609-623

Clark-Arxer, I. (2010), "Cuba". In: UNESCO Science Report 2010.The Current Status of Science around the World, UNESCO Publishing, Paris, pp. 123-132.

Corlan, D. (2012), "Medline spatial trends for dengue 2008-2012" available at: http://dan.corlan.net/medline_spatial_trend/e6kbELom/JCSindex.html

Daar, A.S., Thorsteinsdottir, H., Martin, D.K., Smith, A.C., Nast, S. and Singer, P. (2002), "Top ten biotechnologies for improving health in developing countries", Nature Genetics, Vol. 32, pp. 229-232.

De Vos, P., Garcia-Farinas, A., Alvarez-Perez, A., Rodriguez-Salva, A., Bonet-Gorbea, M. and Van de Stuyft, P. (2012), "Public health services, an essential determinant of health during crisis. Lessons from Cuba, 1989-2000", Tropical Medicine and International Health, Vol.17, pp. 469-479.

Docquier, F. and Rapoport, H. (2012), "Globalization, brain drain, and development", Journal of Economic Literature, Vol. 50, pp. 681-730. 
Falagas, M.E., Pitsouni, E.I., Malietzis, G.A. and Pappas, G. (2008), "Comparison of PubMed, Scopus, Web of Science, and Google Scholar: strengths and weaknesses", FASEB Journal, Vol. 22, No.2, pp. 338-342.

Feinsilver, J.M. (1993), Healing the Masses: Cuban Health Politics at Home and Abroad, University of California Press, Berkeley.

Galvez, A., Maqueda, M., Martinez-Bueno, M. and Valdivia E. (2000), "Scientific publication trends and the developing world. What can the volume and authorship of scientific articles tells us about scientific progress in various regions", American Scientist, Vol. 88, pp. 526533.

Glänzel, W. (2001) National characteristics in international scientific co-authorship relations. Scientometrics, Vol.51, No.1, pp.69-115.

Guchteneire, P, Koing, M. and Mahroum, S. (2006), Transnational Knowledge through diaspora networks, International Journal on Multicultural Societies, Vol.8, No.1, pp. 1-3.

Jones, B.F., Wuchty, S. and Uzzi, B. (2008), "Multi-university research teams: shifting impact, geography, and stratification in science", Science, Vol. 322, pp.1259-1262.

Keck, C.W. and Reed, G.A. (2012) "The curious case of Cuba", American Journal of Public Health, Vol.102, No.8, pp. e13-e22

Le Bail, H. and Shen, W. (2008) "The return of the "brains" to China: what are the social, economic , and political impacts ?" Institut Francaise des Relations Internacionales, Paris, Asie Visions No.11 (November 2008).

Lage-Dávila, A. (2004), "La economía del conocimiento y el socialismo (II): reflexiones a partir del proyecto de desarrollo territorial en Yaguajay", Revista Cuba Socialista, Vol. 33, pp.323.

Lage-Davila, A. (2008) "Connecting immunology research to public health: Cuban Biotechnology. Nature Immunology, Vol 9, No.2, pp. 109-112.

Lage-Dávila, A., (2013) La Economia del Conocimiento y el Socialismo, Editorial Academia, Habana.

López-Mola, E., Silva, R., Acevedo, B., Buxado, J.A.,Aguilera, A. and Herrera L. (2006) "Biotechnology in Cuba: 20 years of scientific, social and economic progress", Journal of Commercial Biotechnology, Vol. 13, pp. 1-11.

Luukkonen, T, Persson, O. and Silvestern, G (1992) Understanding patterns of international scientific collaboration. Science, Technology and Human Values, Vol.17, No.1, pp. 101126.

Mahroum, S., Eldridge, C. and Daar, A. (2006), Transnational diaspora options: How developing countries could benefit from their emigrant population, International Journal on Multicultural Societies, Vol.8, No.1, pp. 25-42. 
Marimón-Torres, N. and Martínez-Cruz, E. (2010) "Evolution of the Cuban medical co-operation during one hundred years of the ministry of public health" (In Spanish). Revista Cubana de Salud Pública, Vol 36, No.3, pp. 254-262.

Miguel, S. (2011) "Revistas y producción científica de América Latina y el Caribe: su visibilidad en SciELO, RedALyC y SCOPUS", Revista Interamericana de Bibliotecología, Vol. 34, pp. 187-199.

Narin, F. and Whitlow, E. S. (1990) Measurement of Scientific cooperation and coauthorship in CEC-related areas of science, Vol.1. Brussels, Commission of the European Communities (CD-NA-12900-EN-C)

Novotny, H, Scott, P. and Gibbons, M. (2003), "Mode 2 revisited: The new production of knowledge", Minerva, Vol.1, No.3, pp.179-194.

Núñez Jover, J. and Lopez Cerezo, J.A.(2008), "Technological Innovation as Social Innovation: Science, Technology and the Rise of STS in Cuba" Science, Technology \& Human Values. Vol. 33, No.6, pp.707-729.

Núñez Jover, J. (2010), Conocimiento academico y sociedad: Ensayos sobre política universitaria de investigación y post-grado. Editorial UH, Habana.

NSF (2000) National Science Foundation. Science and Engeneering indicators 2000. Patterns of International co-authorship in S\&E, Appendix table 6-61, pp. A450-A458. Internet accessed on 20/07/2014 www.nsf.gov/statistics/seind00.pdf/c6/co6.pdf

NSF (2014) National Science Foundation. Science and Engeneering indicators 2014.International co-authored S\&E articles by selected regions/countries/economies, 19972012, Appendix table 5-56. Internet accessed on 20/07/2014 www.nsf.gov/ststistics/seind14/index.cfm/appendix

Pérez-Ones, I. and Núñez-Jover, J. (2009), "Higher education and socio-economic development in Cuba: high rewards of a risky high tech strategy". Science Policy, Vol. 36, pp. 97-101.

Plume, A. (2012), "The evolution of brain drain and its measurement" Part 1. Research Trends, Issue 26, pp.13-14.

Price, D.de S. (1963), "Little science, Big Science ". Columbia University Press, New York.

Price, D.d D., Beaver, D.dB. (1966), Collaboration in an invisible college, The American Psycologist, Vol. 21, N0.11, pp1011-1018.

Reid-Henry, S.M. (2010), The Cuban cure: Reason and Resistance in Global Science, The University of Chicago Press, Chicago.

Reveiz, L., Elias, V., Terry, R.F., Alger, J. and Becerra-Posada, F. (2013), "Comparison of national health research priority-setting methods and characteristics in Latin America and the Caribbean, 2002-2012”. (English) Revista Panamerica de Salud Pública, Vol. 34, 
No.1, pp.1-13.

Sáenz, T.W., Thorsteinsdóttir, H. and de Souza, M.C. (2010), "Cuba and Brazil: an important example of South-South collaboration in health biotechnology", MEDICC review, Vol. 12, pp. 32-35.

Sancho, R. (1992), "Misjudgments and shortcomings in the measurement of scientific activities in less developed countries", Scientometrics, Vol. 23, No.1, pp. 221-233.

Sancho, R., Morillo, F., De Filippo, D., Gomez, I. and Fernandez, M.T. (2006), "Indicadores de la colaboración científica inter-centros en los países de Latinoamerica", Interciencia, Vol. 31, No.4, pp. 284-292.

Sen, B.K. (2010), "Lokta's Law: a view point" Annals of Library and Information Science. Vol 57, June, pp.166- 167.

Stephan, P. (2012), How Economics Shapes Science, Harvard University Press, Cambridge, MASS.

Stone, R. (2015), "In from the cold", Science, Vol.348, Issue 6236, pp.746-751

The Royal Society. (2011), "Knowledge, Networks and Nations: Global Scientific Collaboration in the 21st Century”, March 2011, Report 03/11 DES2096, Elsevier, UK.

Vega-Almeida, R.L., Arencibia-Jorge, R. and Araujo-Ruiz, J.A. (2007), "Scientific production of the health institute in Cuba in the Web of Science from 2000 to 2004, ACIMED, Vol.16 No.3, pp. 1-17.

Wagner, C.S. et al (2000), "Science and Technology Cooperation: Building Capacity in Developing Countries”, Monograph-1357-WB (Santa Monica, California: RAND Corporation)

Wagner, C. S. (2008), “The New Invisible College: Science for Development”. Brookings Institution Press, Washington, D.C.

World Health Organization (2015), International Statistical Classification of Diseases, $10^{\text {th }}$ revision, ICD-10, online. http://www.who.int/classifications/icd/en/. Accessed on 16 August 2015.

Zacca-González, G., Chinchilla-Rodríguez, Z., Vargas-Quesada, B. and de Moya Anegon, F. (2014) "Bibliometric analysis of regional Latin America's scientific output in Public Health through SCImago Journal \& Country Rank". BMC Public Health, Vol. 14, pp. $632-$ 643.

Zacca-González, G., Chinchilla-Rodríguez, Z., Vargas-Quesada, B. and de Moya Anegón, F. (2015) "Pattern of communication and impact of Cuban scientific output in public health". Revista Cubana de Salud Pública, Vol.41, No.2, pp.200-216. 
Figure 1. Diagram of the experimental design

DATABASE




Table 1

Cuban scientific articles in PubMed and those retrieved from electronic journals linked to PubMed (eJ-PubM) indicating the scientific collaboration

\begin{tabular}{|c|c|c|c|c|c|}
\hline Year & $\begin{array}{c}\text { Nr articles in } \\
\text { PubMed }\end{array}$ & $\begin{array}{c}\text { Nr articles in } \\
\text { e-Journals } \\
\text { (eJ-PubM) }\end{array}$ & $\begin{array}{c}\text { Non } \\
\text { collaborative } \\
\text { articles }\end{array}$ & $\begin{array}{c}\text { Collaborative } \\
\text { articles }\end{array}$ & $\begin{array}{c}\text { Collaboration } \\
(\%)\end{array}$ \\
\hline 2000 & 236 & 147 & 83 & 64 & 43.5 \\
\hline 2005 & 304 & 241 & 107 & 134 & 55.6 \\
\hline 2010 & 321 & 258 & 67 & 191 & 74.0 \\
\hline total & 861 & 646 & 257 & 389 & 60.2 \\
\hline
\end{tabular}

17 
Table 2

Distribution of Cuban institutions according to the outputs in eJ-PubM and their principal functions

\begin{tabular}{|c|c|c|c|c|c|c|c|c|c|c|}
\hline $\begin{array}{c}\text { Categories of } \\
\text { Institutions }\end{array}$ & $\begin{array}{c}\mathrm{HE} \\
\text { (S\&T) }\end{array}$ & $\begin{array}{c}\text { HE- } \\
\text { Medicine } \\
\text { School }\end{array}$ & $\begin{array}{c}\text { Teaching } \\
\text { Hospitals }\end{array}$ & R\&D & $\begin{array}{c}\text { R\&D\&P } \\
\text { or } \\
\text { R\&D\&S }\end{array}$ & $\begin{array}{c}\text { R\&D } \\
\text { (non } \\
\text { Health } \\
\text { related) }\end{array}$ & $\begin{array}{c}\text { Research } \\
\text { Institutes/ } \\
\text { (Hospital) }\end{array}$ & $\begin{array}{c}\text { Centres } \\
\text { aiming to } \\
\text { improve } \\
\text { Public Health }\end{array}$ & $\begin{array}{c}\text { GH \& } \\
\text { SH }\end{array}$ & $\begin{array}{c}\mathrm{P} / \mathrm{S} \\
\text { Total }\end{array}$ \\
\hline Core & 6 & 1 & 0 & 2 & 5 & 0 & 6 & 0 & 0 & $\mathbf{2 0}$ \\
\hline Secondary & 2 & 1 & 0 & 1 & 3 & 5 & 13 & 0 & 0 & 0 \\
\hline Periphery & 4 & 7 & 26 & 12 & 4 & 19 & 12 & 28 & 33 & 11 \\
\hline
\end{tabular}

HE: Higher Education

S\&T: Science and Technology

R\&D: Research and Development

R\&D\&P: Research, Development and Production

R\&D\&S: Research, Development and Services

R\&S: Research and Services

GH: General Hospitals

SH: Specialised Hospitals (Maternity, Orthopaedic, Children, etc.)

P/S: Production and /or Services 
Table 3

Net and Institutional Publications per group of Cuban Institutions (aggregates for years 2000, 2005, 2010)

\begin{tabular}{|c|c|c|c|c|c|c|c|c|}
\hline Groups & N & TNP & $\begin{array}{c}\text { Collaborative } \\
\text { (\%) }\end{array}$ & TIP & N & NN & NI & NNI \\
\hline CENTRAL & 205 & 497 & 59 & 630 & 205 & 164 & 144 & 117 \\
\hline MIDDLE & 25 & 82 & 70 & 144 & 25 & 72 & 17 & 30 \\
\hline DISTAL & 27 & 67 & 60 & 206 & 27 & 109 & 18 & 52 \\
\hline Sub-total & 257 & 646 & 60.2 & 980 & 257 & 345 & 179 \\
\hline
\end{tabular}

TNP: Total Net Publications; TIP: Total Institutional Publications, N, NN, NI and NNI are types of collaborations (see text) 
Figure 2
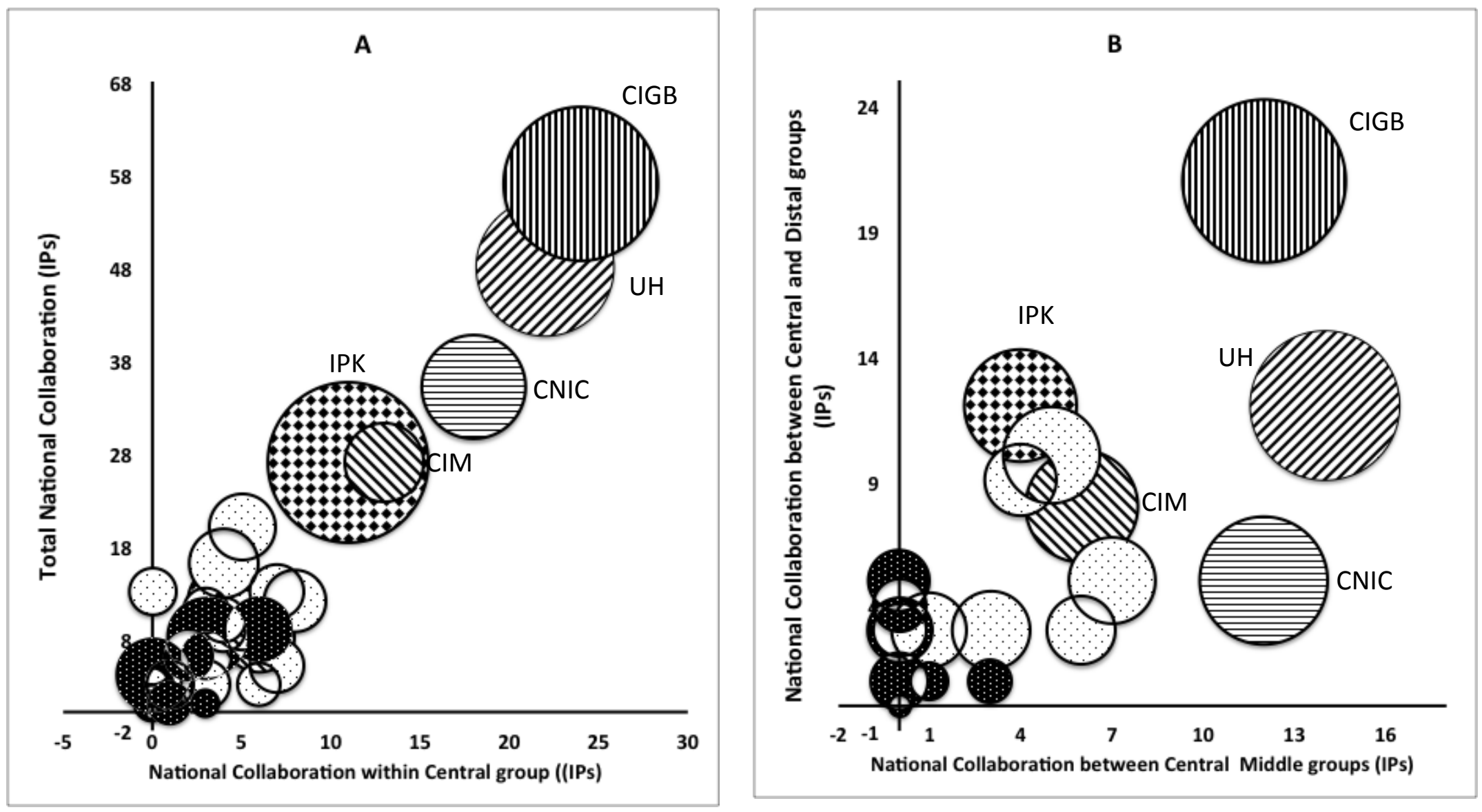
Figure 3

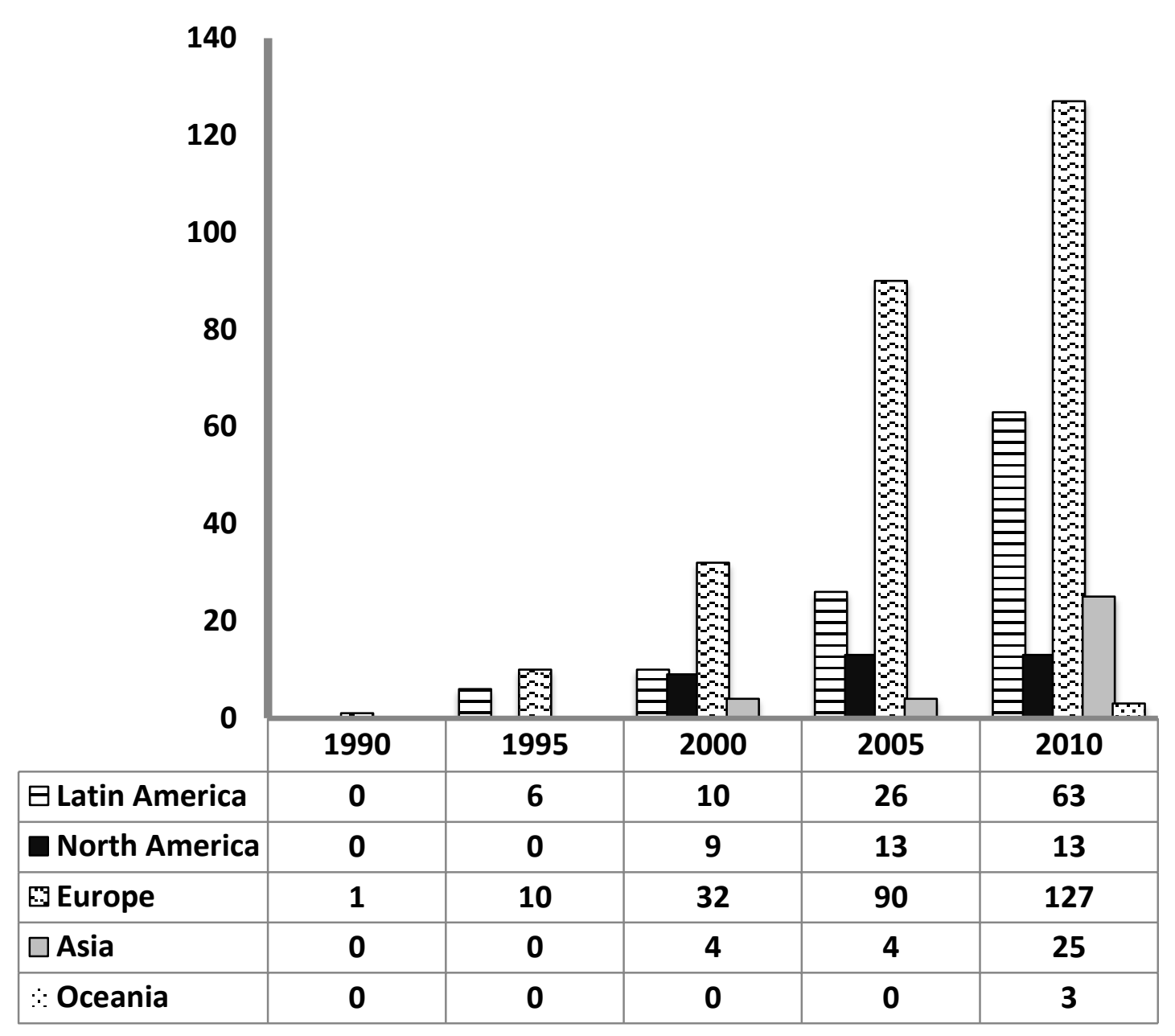


Figure 4

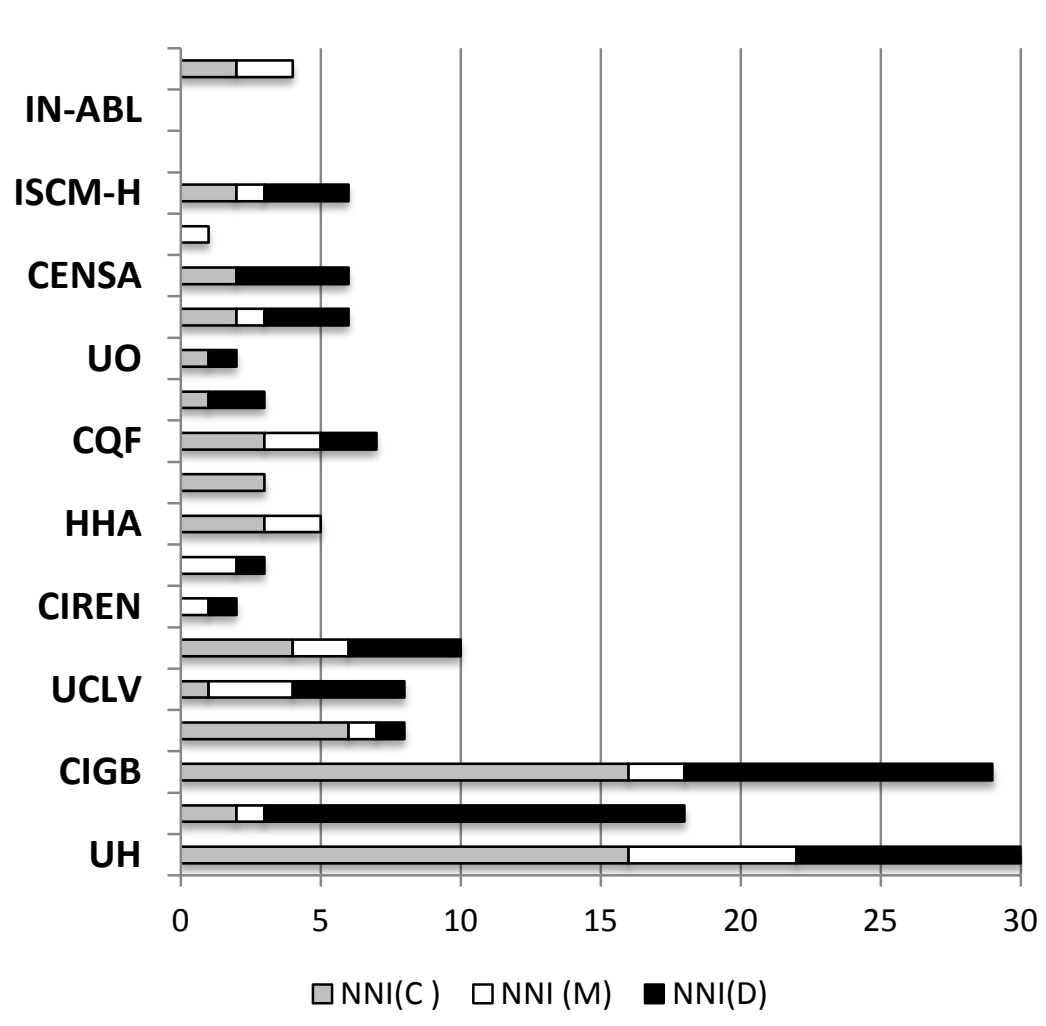

\begin{tabular}{|c|c|c|c|c|}
\hline & $\mathrm{NNI}(\mathrm{C})$ & $\mathrm{NNI}(\mathrm{M})$ & $\mathrm{NNI}(\mathrm{D})$ & total papers \\
\hline UH & 16 & 6 & 8 & 104 \\
\hline IPK & 2 & 1 & 15 & 141 \\
\hline CIGB & 16 & 2 & 11 & 130 \\
\hline CNIC & 6 & 1 & 1 & 59 \\
\hline UCLV & 1 & 3 & 4 & 36 \\
\hline CIM & 4 & 2 & 4 & 34 \\
\hline CIREN & 0 & 1 & 1 & 31 \\
\hline INN & 0 & 2 & 1 & 26 \\
\hline HHA & 3 & 2 & 0 & 24 \\
\hline IF & 3 & 0 & 0 & 24 \\
\hline CQF & 3 & 2 & 2 & 21 \\
\hline CNC & 1 & 0 & 2 & 16 \\
\hline UO & 1 & 0 & 1 & 14 \\
\hline InSTEC & 2 & 1 & 3 & 14 \\
\hline CENSA & 2 & 0 & 4 & 13 \\
\hline INOR & 0 & 1 & 0 & 11 \\
\hline ISCM-H & 2 & 1 & 3 & 11 \\
\hline CIE & 0 & 0 & 0 & 11 \\
\hline IN-ABL & 0 & 0 & 0 & 12 \\
\hline UMCC & 2 & 2 & 0 & 11 \\
\hline
\end{tabular}

$\square \mathrm{NNI}(\mathrm{C}) \quad \square \mathrm{NNI}(\mathrm{M}) \quad \square \mathrm{NNI}(\mathrm{D})$ 
Figure 5. Evolution of international collaboration in Cuban scientific articles at the end of XX century. Internationally coauthored articles (\%) in S\&E in some countries in Latin America.

Graphic made by the author using data from National Science Foundation (NSF) S\&E indicators in 2000. Appendix 6-61 pp. A450-A

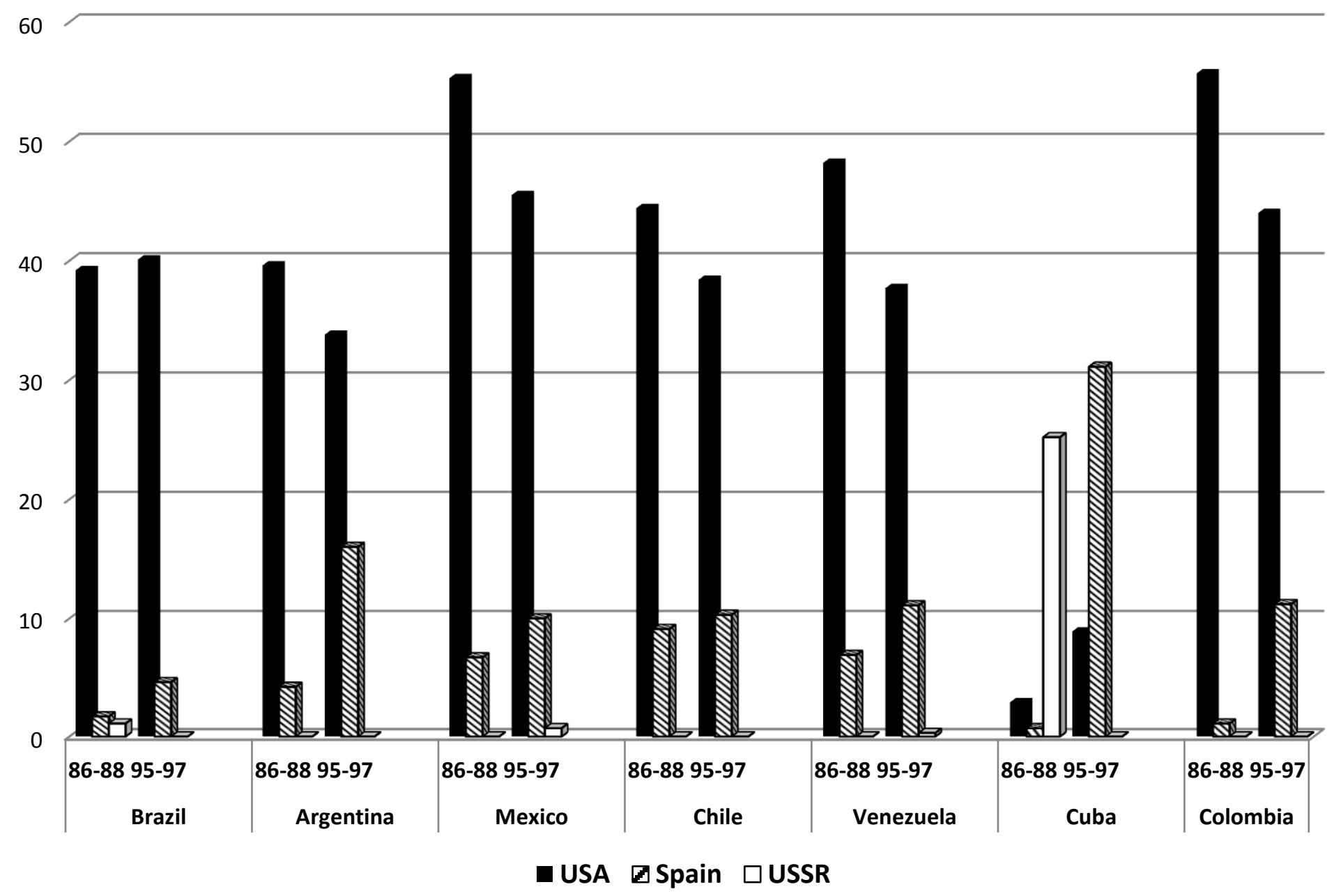


Figure 6
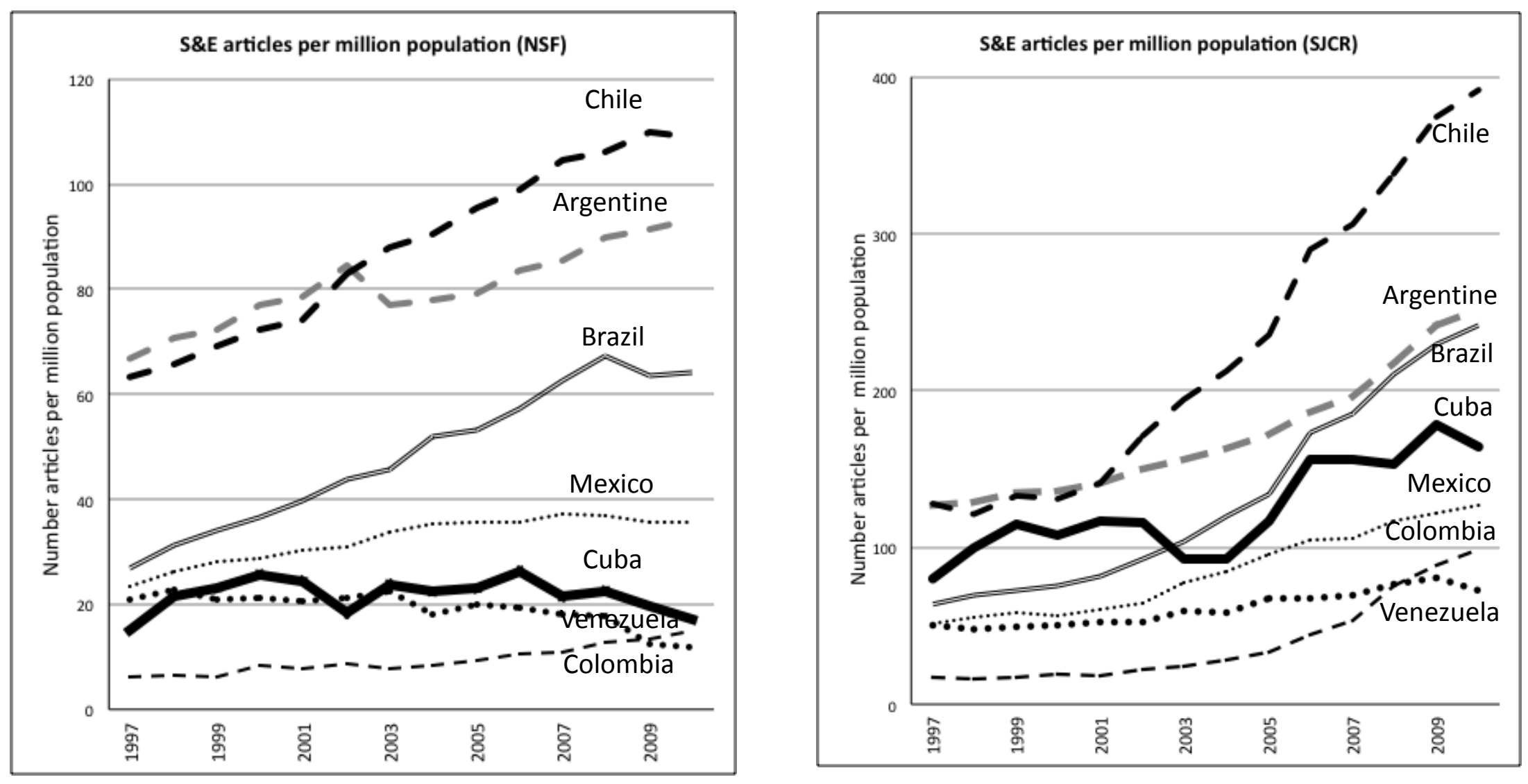


\begin{tabular}{|c|c|c|c|}
\hline \multicolumn{4}{|c|}{$\begin{array}{l}\text { COLLABORATIVE ARTICLES BY DISCIPLINES } \\
\text { (Aggregate net publication of year 2000, } 2005 \text { and 2010) }\end{array}$} \\
\hline $\begin{array}{c}\text { Group of related } \\
\text { disciplines }\end{array}$ & Relevant discipline & $\begin{array}{l}\text { All Net Publ } \\
\text { (aggreagate) }\end{array}$ & \begin{tabular}{|c|}
$\begin{array}{c}\text { Collaborative } \\
\text { articles }\end{array}$ \\
\end{tabular} \\
\hline IMMUNOL/ MICROBIOL & \begin{tabular}{|l} 
IMMUNOLOGY \\
MICROBIOLOGY/PARASITOLOGY
\end{tabular} & 127 & 58 \\
\hline MEDICINE & \begin{tabular}{|l|} 
CLINICAL MEDICINE \\
EPIDEMIOLOGY \\
DENTISTRY \\
PUBLIC HEALTH \\
\end{tabular} & 98 & 47 \\
\hline $\begin{array}{l}\text { BIOCHEM/ GENETICS/ } \\
\text { MOL BIOL/ BIOTECHNOL }\end{array}$ & \begin{tabular}{|l|} 
BIOCHEM/BIOPHYS/BIOINF \\
CELL BIOLOGY/MOL BIOLOGY \\
GENETICS \\
GENETIC ENGINEERING \\
BIOTECHNOLOGY \\
\end{tabular} & 119 & 72 \\
\hline CHEMISTRY & \begin{tabular}{|l|} 
ANALYTICAL CHEMISTRY \\
PHYS CHEMISTRY \\
MEDICINAL CHEMISTRY \\
CHEM ENGINEERING \\
COMPUTATIONAL CHEMISTRY \\
\end{tabular} & 104 & 76 \\
\hline PHYSICS & \begin{tabular}{|l|} 
MEDICAL PHYSICS/ENGINERING \\
PHYSICS \\
\end{tabular} & 27 & 18 \\
\hline MATHEMATICS & \begin{tabular}{|l|} 
BIOSTATISTC \\
MATHEMATICS \\
\end{tabular} & 11 & 7 \\
\hline NEUROSCIENCES & NEUROSCIENCES & 37 & 32 \\
\hline \begin{tabular}{|l|} 
PHARMACOL/ TOXICOL/ \\
PHARMACEUTICS \\
\end{tabular} & \begin{tabular}{|l|} 
PHYSIOLOGY \\
PHARMACOLOGY/TOXICOLOGY \\
PHARMACEUTICAL/DRUG DEV \\
\end{tabular} & 91 & 54 \\
\hline BIOLOGICAL SCIENCES & \begin{tabular}{|l} 
PLANT BIOLOGY/ AGRICUL SCI/ VET MED \\
MARINE BIOLOGY \\
\end{tabular} & 27 & 21 \\
\hline \begin{tabular}{|l|} 
INF SCIE \\
\end{tabular} & IINFORMATION SCIENCE & 2 & 1 \\
\hline MULTIDISCIPLINARY & MULTIDISCIPLINARY & 3 & 3 \\
\hline
\end{tabular}

\section{DISCIPLINES}

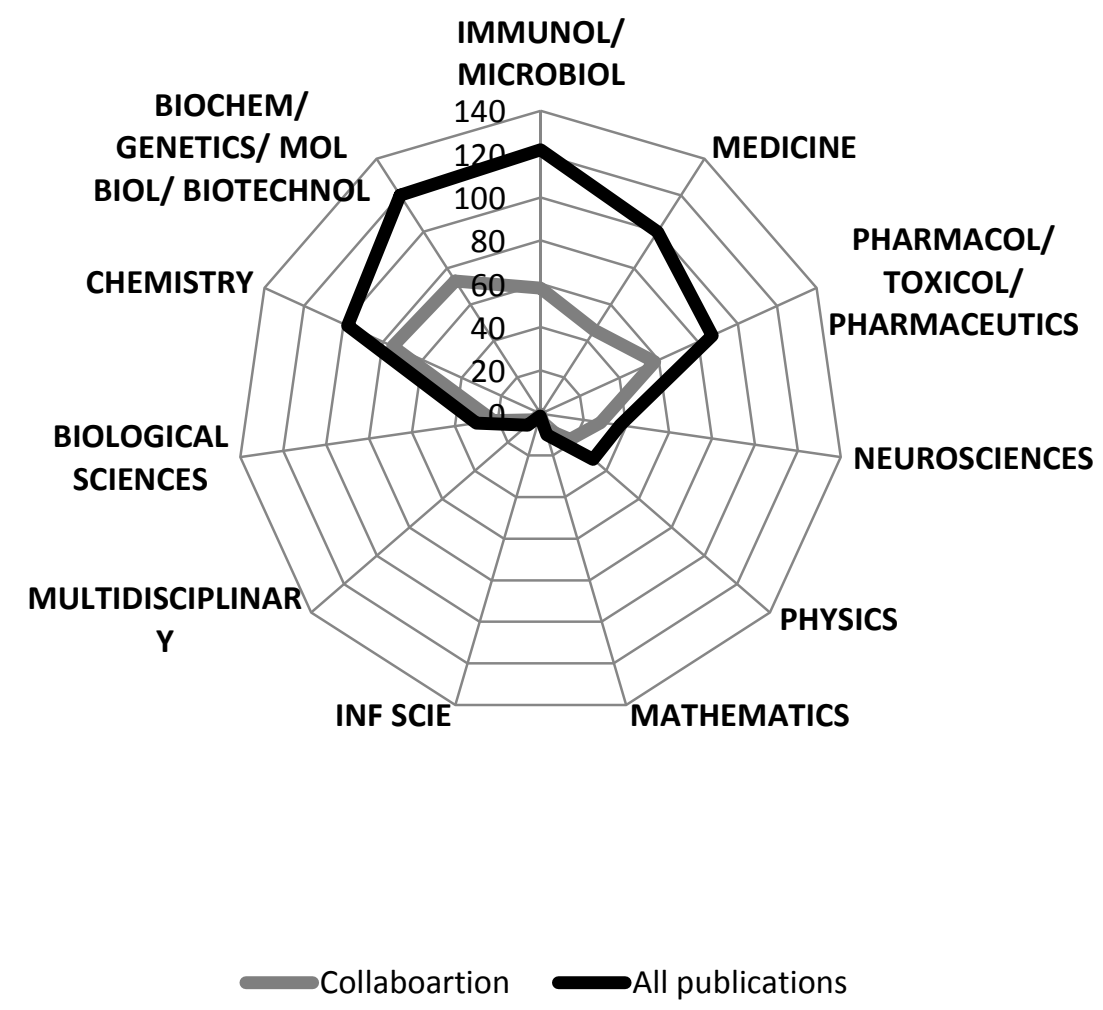

\section{Figure 7}




\section{Figure 8}

\begin{tabular}{|c|c|c|}
\hline SUBJECT (ICD-10) & $\begin{array}{c}\text { Collaborative } \\
\text { publications }\end{array}$ & $\begin{array}{c}\text { All } \\
\text { publications }\end{array}$ \\
\hline INFECTION (I) IMMUNOL(III) & 95 & 143 \\
\hline CANCER (II) & 31 & 41 \\
\hline NERVOUS SYSTEM (V-VI) & 31 & 49 \\
\hline CIRCULATORY SYSTEM (IX) & 14 & 16 \\
\hline METABOLIC DISEASES/ NUTRITION (IV) & 5 & 11 \\
\hline DIGESTIVE SYTEM (XI) & 9 & 9 \\
\hline MATERNITY/ CHILD BIRTH (XV) & 6 & 9 \\
\hline GENITOURINARY (XIV) & 3 & 7 \\
\hline OTHER DISEASES/ DISORDERS & 7 & 8 \\
\hline PUBLIC HEALTH/ PREVENTION/ & 12 & 16 \\
\hline & 213 & 309 \\
\hline
\end{tabular}

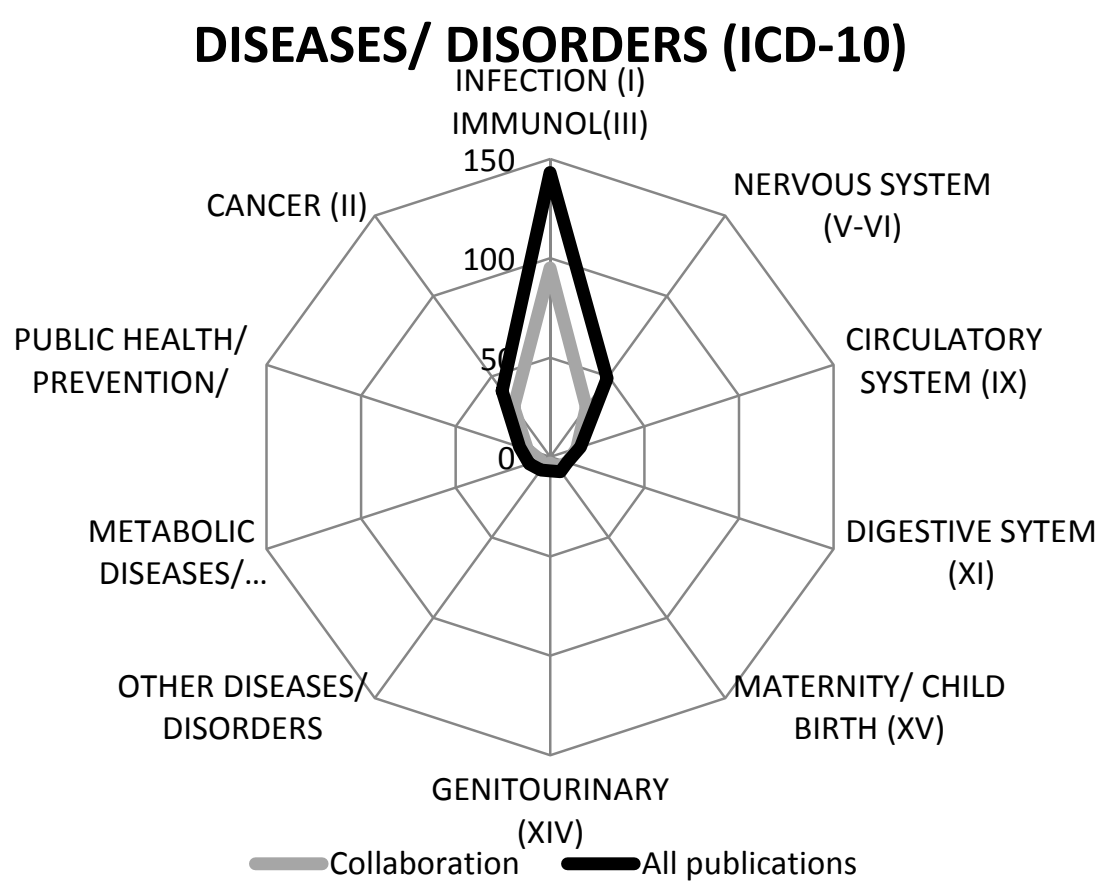




\section{Appendix 1 Institutions in the Central group}

Names of Cuban Institutions (in Spanish), abbreviations and categories (see legend in Table 2)

1. Universidad de la Habana, $\underline{\mathrm{UH}}$ (HE\&R)

2. Instituto de Medicina Tropical Pedro Kourí, IPK (R\&S)

3. Centro de Ingeniería Genética y Biotecnología, CIGB (R, D\&P)

4. Centro Nacional de Investigaciones Científicas, $\underline{C N I C}$ (R\&D)

5. Universidad Central de Villa Clara, UCLV (HE\&R)

6. Centro de Inmunología Molecular, CIM (R, D\&P)

7. Centro Internacional de Restauración Neurológico, CIREN (R\&S)

8. Instituto de Neurología y Neurocirugía, INN (R\&S)

9. Hospital Hermanos Amejeiras, $\mathrm{HHA}$ (R\&S)

10. Instituto Finlay de Investigación y Producción de Vacunas y Sueros, IF (R, D\&P)

11. Centro de Química Farmacéutica, $C Q F(R \& D)$

12. Centro de Neurociencias de Cuba, $\underline{C N C}(R, D \& P / S)$

13. Universidad de Oriente Patricio Lumumba, $\underline{\cup O}$ (HE\&R)

14. Instituto Superior de Ciencias y Tecnologías Aplicadas, InSTEC (HE\&R)

15. Centro Nacional de Sanidad Agropecuaria, CENSA (R, D\&P/S)

16. Instituto de Oncología y Radiobiología, INOR (R\&S)

17. Instituto Superior de Ciencias Médicas de La Habana, ISCM-H (HE\&ResMed)

18. Centro de Inmuno Ensayo, CIE (R, D\&P)

19. Instituto de Nefrología Abelardo Buch López, IN-ABL (R\&S)

20. Universidad de Matanzas Camilo Cienfuegos, UM-CC (HE\&R) 


\section{Appendix 2 Institutions in the MIDDLE group}

Names of Cuban Institutions (in Spanish), abbreviations and categories (see legend in Table 2)

1. Centro de Investigaciones Biológicas, $\underline{C I B}$ (R, D\&S)

2. Instituto Nacional de Endocrinología y Enfermedades Metabólicas, INEEM (R\&SH)

3. Centro Nacional para la Producción de Animales de Laboratorio, CENPALAB (R, D\&P)

4. Instituto Superior de Ciencias Básicas y pre-Clinicas Victoria de Girón, ISCMPC (HE\&R)

5. Centro Nacional Coordinador de Ensayos Clínicos, CENCEC (R\&S)

6. Instituto de Cardiología y Cirugía Cardiovascular,(ICCC) (R\&SH)

7. Instituto Nacional de Gastroenterologia, ING (R\&SH)

8. Instituto Nacional Hematología e Inmunología, INHI (R\&SH)

9. Instituto de Cibernética, Matemática y Física, ICIMAF (R\&D)

10. Centro Nacional de Genética Médica, CNGM (R\&SH)

11. Instituto Cubano de Oftalmología, ICO-RPF (R\&SH)

12. Centro de Investigaciones Médico Quirúrgicas, CIMEQ (R\&SH)

13. Centro de Investigaciones y Asistencia Médica para Ataxia Cubana, $\underline{\mathrm{CIRAH}}$ (R\&SH)

14. Instituto Cubano de Investigaciones de los Derivados de la Caña de Azúcar, ICIDCA (R\&D)

15. Instituto de Ecología y Sistemática, IES (R\&D)

16. Centro de Bioactivos Marinos, CEBIMAR (R\&D)

17. Centro de Estudios Aplicados al Desarrollo Nuclear, CEADEN (R\&D)

18. Estación Experimental para Caña de Azúcar, Cienfuegos, EECA-C (R, D\&P)

19. Instituto Superior Politécnico José Antonio Echeverría, ISPJAE (HE\&R)

20. Instituto de Medicina Militar, IMM-LDS (HE\&R)

21. Hospital Universitario -Gustavo Aldereguía, HU-GAL (R\&GH)

22. Centro de Protección e Higiene de las Radiaciones, CPHR (R\&S)

23. Dirección Nacional del MINSAP, DN-MINSAP (R\&S)

24. Centro de Investigación y Desarrollo de Medicamentos, CIDEM (R\&D)

25. Centro Nacional de Biopreparados, BIOCEN (R, D\&P) 


\title{
Appendix 3 Institutions in the DISTAL group
}

\author{
Names of Cuban Institutions (in Spanish), abbreviations and categories (see \\ legend in Table 2)
}

1. Centro de Isótopos, $\underline{C E N T I S}$ (R, D\&S)

2. Centro Nacional de Bioinformática, NBioC (S\&T)

3. Escuela Latinoamericana de Salud Pública, ELAM (R, D\&P)

4. Universidad de Ciego de Avila, UNICA (HE\&R)

5. Universidad de Cienfuegos, UCF (HE\&R)

6. Universidad de Pinar del Río, UPR (HE\&R)

7. Universidad Agraria de la Habana y Colegio de Medicina Veterinaria, UACMV (HE\&R)

8. Instituto de Oceanología, IO (S\&T)

9. Instituto de Geografía Tropical, IGT (S\&T)

10. Centro de Ingeniería Genética y Biotecnología-Camagüey, CIGB-Ca (R,D\&P)

11. Centro de Ingeniería Genética y Biotecnología-Sancti Spiritu, CIGB-SS (R,D\&P)

12. Centro de Reproducción de la Ictiofauna Indígena, $\underline{C R I I}$ (S\&T)

13. Centro de Investigaciones de Ecosistemas Costeros, CIEC (S\&T)

14. Centro de Estudios Ambientales de Cienfuegos, CEACi (S\&T)

15. Centro de Desarrollo de Equipos e Instrumentos Científicos, CDEIC (R\&D)

16. Centro de Investigaciones para la Mejora Animal, CIMA (R\&D)

17. Centro de Investigaciones Clínicas, $\underline{C l C}$ (R\&S)

18. Instituto de Angiología y Cirugía Vascular, IACV (R\&SH)

19. Instituto Nacional de Higiene, Epidemiología y Microbiología, INHEM (R\&S)

20. Centro Nacional de Toxicología, CNT (R\&SH)

21. Instituto Nacional de Investigación Fundamental en Agricultura Tropical, INIFAT (S\&T)

22. Agencia para la Generación de Conocimiento y Tecnología, AGCT (S\&T)

23. Museo de Historia Natural Tomás Romay, BIOECO (S\&T)

24. Centro de Ingeniería Ambiental-Camagüey, CIA-Ca (S\&T)

25. Instituto de Salud Vegetal, ISV (R\&D)

26. Instituto de Ciencia Animal, ICA (R\&D)

27. Escuela Nacional de Salud Pública, SNSP (HE\&R)

28. Instituto Superior de Ciencias Médicas de Villa Clara, ISCM-VC (HE\&R)

29. Instituto Superior de Ciencias Médicas de Matanzas, ISCM-Ma (HE\&R)

30. Instituto Superior de Ciencias Médicas de Camagüey, ISCM-Ca (HE\&R)

31. Instituto Superior de Ciencias Médicas de Santiago de Cuba, ISCM-SC (HE\&R)

32. Instituto Superior de Ciencias Médicas de Bayamo, ISCM-Ba (HE\&R)

33. Instituto de Nutrición e Higiene de Alimentos, INHA (R\&D)

34. Centro Iberoamericano para la Tercera Edad, CITED (R\&SH)

35. Instituto de Medicina Legal, IML (R\&SH)

36. Instituto de Medicina del Deporte, IMD (R\&SH)

37. Centro de Referencia para Investigaciones en Artereosclerosis, CRIA (R\&SH)

38. Centro Nacional de Referencia de Anatomia Patologica, CNRAP (R\&SH)

39. Laboratorio de Investigaciones sobre SIDA, LISIDA (R\&SH)

40. Centro de Genética Médica_Holguin, CGM-Ho (R\&SH)

41. Centro de Investigación sobre Enfermedades Infecciosas, CIEI (R\&SH)

42. Hosp. Clínico Quirúrgico Doc. Manuel Asunce Domenech- Camagüey, HCQD-Ca HE\&SH)

43. Hospital Universitario Provincial A. Milán Castro-Santa Clara, HUP-VC (HE\&SH)

44. Escuela de Medicina de la Habana, Hosp Julio Trigo, EMJT-H (HE\&SH)

45. Hospital General Docente Dr. Ernesto Guevara Serna, Las Tunas, HGD-EGS-H (HE\&SH)

46. Hosp. Prov. Doc. Clínico Quirúrgico A. Luaces Iraola, Ciego de Avila, HPDCQ-CiAv (HE\&SH)

47. Hospital Universitario "Gral. Calixto García", HU-GCG (HE\&SH)

48. Hospital General Docente "Carlos J. Finlay", HGD-CJF (HE\&SH)

49. Hospital Universitario "Cmdte. Faustino Pérez", HU-CFP (HE\&SH)

50. Hospital General Docente Matanzas"J. R. López Tabranes", HGDMa-JRLT (HE\&SH) 
51. Hospital General Docente Enrique Cabrera, HGD-EC (HE\&S)

52. Hospital Pediátrico Universitario "Pedro Borras", HPU-PB (HE\&SH)

53. Hosp. Pediátrico Universitario-Cienfuegos "P. González Cueto", HPU-PGC-Ci (HE\&SH)

54. Hosp. General Docente-Las Tunas "Guillermo Domínguez", HGD-GD-LT (HE\&S)

55. Facultad de Ciencias Médicas "Dr. Miguel Enríquez", HGD-DME (HE\&S)

56. Hospital Docente Clínico Quirúrgico "10 de Octubre", HCQD-DO (HE\&SH)

57. Hospital Pediátrico Docente-Villa Clara "José Luis Miranda", HPD-VC (HE\&SH)

58. Hospital Clínico Quirúrgico Docente "Dr. Salvador Allende", HCQD-DSA (HE\&SH)

59. Hospital Pediátrico Universitario "Juan Manuel Márquez", HPU-JMM (HE\&SH)

60. Facultad de Medicina Finlay-Albarrán, Marianao, HGD-FAM (HE\&SH)

61. Clínica Dental Docente "Raúl González Sanchez", CDD-RGS (HE\&SH)

62. Clínica Dental Docente de Bauta, CDD-B (HE\&SH)

63. Hosp. Clínico-Quirúrgico Docente "Cmdte. Manuel Fajardo", HCQD-MF (HE\&SH)

64. Hosp. Quirúrgico Universitario-Pinar del Río "Abel Santa Maria", HCQD-PR (HE\&SH)

65. Hosp. General Docente-Holguin "Vladimir Ilich Lenin" HGD-Ho (HE\&S)

66. Hosp. General Docente- Bayamo "Carlos Manuel de Céspedes", HGD-Ba (HE\&S)

67. Policlínico Docente- Camagüey “José Martí, PD-Ca (HE\&S)

68. Hospital Pediátrico de Camagüey, HP-Ca (S)

69. Cardiocentro-Santa Clara "Ernesto Che Guevara", CC-VC (SH)

70. Hospital Gineco-Obstétrico "Eusebio Hernández", HGO-EH (SH)

71. Hospital Pediátrico de San Miguel del Padrón, HPSMP (SH)

72. Hospital Pediátrico "William Soler", HPWS (SH)

73. Hospital Neumológico Nacional Benéfico Jurídico, HNNBJ (SH)

74. Hospital Psiquiátrico "Eduardo Bernabé Ordaz", HPsEBO (SH)

75. Hospital Psiquiátrico "Gali Garcia", $\mathrm{HPsGG}$ (SH)

76. Hospital Provincial de Ciego de Avila, $\underline{\mathrm{HP}-\mathrm{CiA}}$ (S)

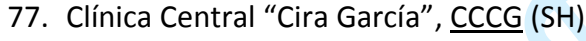

78. Hospital Infantil Sur- Santiago de Cuba, HIS-SC (SH)

79. Hospital Gíneco-Obstétrico "América Arias", HGO-AA (SH)

80. Hospital_Santiago Cuba "Conrado Benítez"

81. Hospital Gíneco-Obstétrico "R. González Coro" HGO-RGC (SH)

82. Hospital Pediátrico "Leonor Pérez", HP-LP (SH)

83. Hospital "Freire de Andrade", HFA (S)

84. Hospital de Camagüey "María Curie", HMC-Ca (S)

85. Hospital de Villa Clara "Celestino Hernández Robau",

86. Hospital de Camagüey "Amalia Simoni", HAS-Ca (S)

87. Hospital Rural de Limonar, Matanzas HRL-Ma (S)

88. Hospital de la Isla de la Juventud "Héroes de Baire", HHB-IJ (S)

89. Policlínico de la Isla de la Juventud "Orestes Falls Oñat", POFO-IJ (S)

90. Policlínico de la Isla de la Juventud "J. M. Páez Incháustegu", PJMPI-IJ (S)

91. Policlínico de la Isla de la Juventud "Leonilda Tamayo Matos", PLTM-IJ (S)

92. Centro de Atencion Primaria de Salud "Corynthia", CAPS (S)

93. Policlínico "26 de Julio", PVJ (S)

94. Hospital Pediátrico de Centro Habana, $\mathrm{HPCH}(\mathrm{SH})$

95. Clinica Dental de Caimito, $\underline{C D C}(\mathrm{~S})$

96. Policlinico "19 de Abril", PDA (S)

97. Hospital Pediátrico de Centro Habana, $\mathrm{HPCH}$ (SH)

98. Sociedad Cubana de Esclerosis Múltiple, SCEM (R\&SH)

99. Laboratorio Central de Criminalística, LCC (R\&SH)

100.Centro de Control Estatal de Equipos Médicos, CCEEM (R\&S)

101.Centro Nacional para el Control Estatal de la Calidad de los Medicamentos, CECMED (S)

102.Centro Nacional de Información de Ciencias Medicas, CNICS (S)

103.Centro de Protección e Higiene del Trabajo, CNPHT (R\&SH)

104.Centro Nacional para la Educación y Promoción de Salud, CNPES (S)

105.Centro para el Desarrollo de la Epdemiología, CDE (R\&SH)

106. Unidad Nacional de Salud Ambiental MINSAP, UNASA (R\&S)

107.Centro Prov. Santiago de Cuba de Salud Pública y Epidemiología, CPE-SC (R\&SH) 
108.Centro Provincial de Epidemiología y Higiene, Camagüey, CPHE-Ca (R\&SH)

109.Centro Provincial de Epidemiología y Higiene, Habana, CPHE-H (R\&SH)

110.Centro Provincial de Epidemiología y Higiene, Villa Clara, CPHEVC (R\&SH)

111.Centro Provincial de Epidemiología y Higiene, Ciego de Avila, CPHE-CA (R\&SH)

112.Centro Provincial de Epidemiología y Higiene, Santi Spiritus, CPHE-SS (R\&SH)

113.Centro Provincial de Homeopatía, Granma, CPH-G (S)

114.Centro Provincial de Homeopatía, Holguín, $\mathrm{CPH}-\mathrm{H}$ (S)

115.Centro Provincial de Genética Médica-Habana, CPGM-H (R\&S)

116. Unidad Prov. de Vigilancia y Lucha Antivectorial, Sancti Spíritu, LAV-SS (S)

117. Unidad Prov. de Vigilancia y Lucha Antivectorial, Santiago de Cuba, LAV-SC (S)

118.Centro Municipal de Higiene y Epidemiología de Bayamo, CMHE-Ba (S)

119.Centro Municipal Vigilancia y Lucha Antivectorial de Boyeros, CMLA-H (S)

120.Centro Municipal Higiene y Epidemiología de Guanabacoa, CMHE-G (S)

121.Centro Municipal de Higiene y Epidemiología de Holguin, CMHE-Ho (S)

122.Centro Municipal de Higiene y Epidemiología de Regla, CMHE-R (S)

123.Centro Municipal de Higiene y Epidemiología de Habana Vieja, CMHE-HV (S)

124.Centro Municipal de Higiene y Epidemiología de Centro Habana, CMHE-CH (S)

125.Centro Municipal de Higiene y Epidemiología de Boyeros, CMHE-Bo (S)

126. Unidad Prov. Vigilancia y Lucha Antivectorial, Cumanayagua, Cienfuegos, LAC-Ci (S)

127.Centro Municipal de Higiene y Epidemiología de Playa, CMHE-PI (S)

128.Centro Municipal de Higiene y Epidemiología de Isla de la Juventud, CMHE-IJ (S)

129.Grupo Empresarial Agromin, GEA (P)

130.Empresa Importadora y Exportadora de Medicamentos y Equipos Medicos, MEDICUBA (S)

131.Laboratorios Biológicos Farmacéutico, LABIOFAM (P)

132. Laboratorios Farmacéutico, AICA (P)

133.Laboratorios MedSOL, MEDSOL (P)

134.Laboratorio de Anticuerpos y Biomodelos Experimentales, LABEX (P)

135.Centro de Quimica Biomolecular Antígenos Sínteticos, CQB (R\&D)

136. Grupo Empresarial de Producciones Biofarmacéuticas y Químicas, GEPBQ (R\&D)

137. Laboratorios Farmacéuticos LIORAD, LIORAD (P)

138. Centro de Investigaciones Científicas de la Defensa Civil, CICDC (R\&S)

139. Instituto de Investigaciones de Raíces Tropicales, INIVIT (R\&D)

140.Instituto de Investigaciones de la Caña de Azúcar, INICA (R\&D)

141.Instituto Nacional de Investigación de Sanidad Vegetal, INISAV (R\&D)

142. Instituto de Investiagciones del Tabaco, IIT (R\&D)

143.Cooperativa Agrícola "Osvaldo Sánchez", Güines, CAlOS-G (P)

144.Estación Experimental Apícola "El Cano", EEA (R\&D)

145. Instituto Nacional de Ciencias Agrícolas, INCA (R\&D)

146.Centro Nacional de Epizootiología, Diagnóstico e Investigación, CNEDI (R\&D)

147. Instituto de Medicina Veterinaria, IMV (R\&D)

148. Centro Nacional de Parasitología Animal, CNPA (R\&D)

149.Parque Zoológico Nacional, PZN (R\&S)

150. Instituto de Investigaciones para la Industria Alimenticia, IIIA (R\&D)

151.Centro de Investigaciones Pesqueras, CIPq (R\&D)

152.Centro de Investigaciones del Petróleo, $\mathrm{CIPt}$ (R\&D)

153.Grupo para el Desarrollo Integral de la Ciudad, GGIC (R\&D)

154.Centro de Investigación y Desarrollo del Comercio Interior, CIDCI (R\&D)

155.Empresa Nacional de Geofísica, ENGf (P) 